\title{
Fault Model of the 1891 Nobi Earthquake from Historic Triangulation and Leveling
}

\author{
Fred F. Pollitz* and I. Selwyn Sacks \\ Carnegie Institution of Washington, \\ Department of Terrestrial Magnetism, \\ 5241 Broad Branch Road, N.W., \\ Washington, DC 20015, U.S.A.
}

The faulting associated with the 1891 Nobi earthquake, central Honshu, is re-examined on the basis of horizontal displacement vectors determined between the periods 1882/1899-1950/1961. These vectors are modelled in terms of two components: (1) strain accumulation and release along the Nankai Trough and Suruga Trough, and (2) postseismic relaxation following the 1891 earthquake. We assume a rheological model of the central Honshu crust and upper mantle consisting of a 33-km thick elastic lithosphere overlying a $130 \mathrm{~km}$ thick viscoelastic sublithosphere. The modelling demonstrates that the observed displacement vectors are dominated by post-seismic displacements following the Nobi earthquake. The Nukumi-Neodani faults are inferred to have accommodated $7-8 \mathrm{~m}$ of left lateral strike-slip displacement, in good agreement with those estimates based on the observed surface rupture. In addition, we identify two northeast-southwest trending blind thrust faults, together comprising a 70-km-long region of compressional deformation, each of which accommodated several meters of reverse slip during the Nobi earthquake. These thrust faults consist of a $20-\mathrm{km}-\mathrm{long}$ western segment and a 50-km-long eastern segment. The western thrust begins near the southern termination of the strike-slip faulting component, has shallow $\left(31^{\circ}\right) \mathrm{dip}$, is buried by $15 \mathrm{~km}$ and has a prominent coseismic signal in the leveling data. Examination of the topography east of Nagoya suggests that the eastern thrust is buried $5-10 \mathrm{~km}$ below the surface and represents the subterranean continuation of the exposed thrust fault on the eastern flank of the Kiso Range to the northeast. The model of strain accumulation and release includes the various effects of the 1854 Ansei and 1944 Tonankai earthquakes, as well as the effect of steady state Philippine Sea interplate convergence. A model consisting of only tectonic strain accumulation and release along the Philippine Sea interplate boundary provides a poor fit to the data. The modelling suggests that the 1944 rupture did not extend beyond the Atsumi Peninsula. The observed displacement vectors and an independent set of Suruga Bay uplift data contain a moderate signal due to 1854 postseismic displacements. Considering that this signal has tradeoffs with the slip accumulation rate in Suruga Bay, this enables us to constrain the central Honshu sublithospheric viscosity to lie near $2 \times 10^{19} \mathrm{~Pa} \cdot \mathrm{s}$.

Received February 19, 1993; Accepted March 30, 1994

* To whom correspondence should be addressed. Present address: Geophysikalisches Institut, Universitaet Karlsruhe, Hertzstrasse 16, 76187 Karlsruhe, Germany 


\section{Introduction}

The October 28, 1891 Nobi earthquake ( $M$ 8.0; Muramatu, 1962) is the largest onland earthquake ever recorded in the Japanese Islands. As a rare large and destructive inland earthquake, it is important from a number of perspectives. First; the only known surface rupture associated with the event is along the Nukumi Fault-Neodani Fault-Umehara Fault zones (Muramatu, 1976; Mikumo and Ando, 1976) with a total rupture length of about $80 \mathrm{~km}$. Given the magnitude of the event and the broad extent of pre- and post-Nobi seismicity, this suggests the presence of unidentified faults associated with the earthquake. Next, the earthquake is located near the boundary between two major neotectonic provinces in Honshu: that dominated by Philippine Sea plate interactions in southwest Honshu and that dominated by Pacific plate interactions in northeast Honshu. Most importantly, at least from an earthquake prediction perspective, is that the 1891 earthquake occurred along the inland extension of the termination of the 1944 Tonankai earthquake, a great interplate thrust event (Sato and Inouchi, 1975). Whether or not the 1891 earthquake relieved interplate stresses sufficiently to prevent northeast propagation of the 1944 earthquake (Mogi, 1981), and to what degree it may have done so, has profound implications for the "Tokai earthquake" predicted for central Honshu in the near future (Ishibashi, 1981). This is an especially intriguing question since the tectonics of the entire area are dominated by interplate thrust events, while the Nukumi-Neodani faults accommodated about 2-8 $\mathrm{m}$ (meters) of left-lateral strike-slip motion during the 1891 event. A quantitative study of the faulting associated with the 1891 event, including whether or not the 1891 earthquake also had a thrust component (which has not yet been recognized), would not only alter the estimates of seismic hazard for the Tokai region but also clarify the long-term tectonic behavior of central Honshu as it responds to the different tectonic stresses exerted on it by the Izu-Ogasawara ridge to the east (Huchon and Angelier, 1987) and the Zenisu Ridge and Philippine Sea oceanic crust to the south and southwest (Chamot-Rooke and LePichon, 1989; Lallemant et al., 1989).

Related to the determination of the type and amount of slip associated with the 1891 event is the determination of a first order rheological model for central Honshu. Thatcher et al. (1980) and Rydelek and Sacks $(1988,1990)$ have shown for northeast Honshu that the crustal deformation observed over a period of several decades may be successfully modelled in terms of the dynamic behavior of an elastic plate overlying a viscoelastic layer or halfspace. This rheological model, combined with the assumption of a linear stress-strain relation, has allowed Thatcher et al. (1980) and Rydelek and Sacks (1990) to model triangulation data observed in the early-mid 1900's in terms of postseismic relaxation of the earth following the $1896 \mathrm{Riku}-\mathrm{U}$ earthquake. The fundamental results of these studies are that: 1 . The strain field continues to evolve in an observable fashion for several decades following a great earthquake, and 2. The evolution of this strain field is both time-dispersive and space-dispersive. These properties have allowed sublithospheric viscosity to be estimated from historic triangulation data sets observed in the decades following a great earthquake, and for fault slip estimates to be obtained for the earthquake, even when the observation errors of the networks are high by today's standards. The viscosity can generally be recovered within fairly 
narrow limits because of the spatial and temporal dependence of the postseismic crustal deformation on sublithospheric viscosity. A detailed analysis of this type, involving the determination of both the slip distribution and sublithospheric viscosity from historic triangulation data, has been performed by Pollitz and Sacks (1992) for the 1857 Fort Tejon earthquake, southern California. Among previous studies of Japan, we would like to draw attention to those by Tabei (1989), who inferred the presence of both postseismic motions and tectonic strain accumulation in geodetic data (near the 1927 Tango earthquake), and Miyashita (1987), who synthesized pre-, co-, and postseismic observations in terms the superposition of steady state tectonic strain accumulation and postseismic relaxation (applied to the 1946 Nankaido earthquake). Miyashita's study verified quantitatively the findings of Thatcher (1984), who characterized in detail the geodetic observations in terms of the same framework.

In this paper, we shall investigate the type and distribution of slip associated with the 1891 Nobi earthquake. To better understand the tradeoffs involved with our analysis, we examine the data with two sets of observational constraints. In the first analysis, we model horizontal displacement vectors in terms of postseismic relaxation. We shall employ a data set consisting of horizontal displacement vectors observed between the periods 1882/1899 and 1950/1961 as determined by Harada and Isawa (1969) in central Honshu. At the outset, we shall assume that the Maxwell relaxation time and elastic plate thickness obtained for northeastern Honshu are appropriate for modelling postseismic relaxation in central Honshu. Since subsequent analysis shows these to be good assumptions, we are in a position to concentrate here on modelling the slip associated with the 1891 earthquake. In this analysis, we constrain the positions of various candidate fault segments, but allow the inversion to determine the slip. The slip of the Neodani Fault is known (Muramatu, 1976), and the fact that our inversion independently yields an accurate estimate of this slip is strong confirmation of the stability of the method used. We shall find a new result, that in addition to several meters of left-lateral slip along the Nukumi-Neodani faults, the 1891 Nobi earthquake was accompanied by several meters of slip along two large buried thrust structures underlying the Tokai Province, about $50 \mathrm{~km}$ inland from the Pacific Ocean. Because this result is so unexpected after more than 100 years of thought on the matter, we shall devote considerable space to describing the steps of reasoning we took in arriving at this result. This will involve four sets of inversions using Harada and Isawa's geodetic data. In the second analysis, we shall take advantage of additional constraints, many of which were previously discussed by Mikumo and Ando (1976), in order to estimate fault slip and geometry beyond the visible traces. We shall provide evidence supporting the existence of the blind thrust faults on the basis of seismicity, the topography pattern, and leveling surveys. Quantitative modelling of the leveling and topography will enable us to estimate the depth of burial of the faults and the total offset of the eastern thrust segment in Quaternary time.

We emphasize that modelling of postseismic relaxation places constraints on the overall seismic moment release and general location of faulting. Thus, as far as the thrust faults are concerned, the postseismic modelling results are only rough approximations. The additional information form topography and, particularly, leveling data will enable us to further refine the spatial extent and geometry of faulting.

Vol. 42, No. 1, 1994 


\section{Data Set and Modelling}

The data set for this study consists of horizontal displacement vectors determined for Honshu Island by Harada and Isawa (1969). These have been determined using triangulation surveys conducted on Honshu Island between the periods $1882 / 1899$ and 1950/1961. These displacement vectors are well-known and have long been used in studies of seismic hazard and strain accumulation in various parts of Honshu (Ishibashi, 1981). The known faults associated with the 1891 earthquake are shown in Fig. 1(a) along with the rupture zone of the 1944 earthquake. To include as much data as possible in this study, we wish to extract from this data set those vectors obtained at stations within a $100-\mathrm{km}$ radius of the 1891 rupture zone, but which do not show significant effects from other earthquakes. We have chosen the subset of 22 stations shown in Fig. 1(b), with corresponding displacement vectors plotted in Fig. 2(a). The limits of the chosen data set are mainly determined by the locations of earthquakes occurring between 1891 and 1951 which we seek to avoid, in order to avoid contamination of the crustal deformation data set with their coseismic signals. These include the large $(M>7.0) 1923$ Kanto, 1927 Tango, 1930 Kita-Izu, 1944 Tonankai, 1945 Mikawa, and 1948 Fukui earthquakes, and also the 1896 and 1933 earthquakes on the Noto Peninsula (Usami, 1979). Several of the important inland earthquakes are shown in Fig. 1(b). The largest and most significant earthquake in terms of proximity to the 1891 rupture zone is the $M 8.01944$ Tonankai earthquake. Although the employed data at the southern end of the data subset are only about $100 \mathrm{~km}$ from the main rupture zone of the 1944 earthquake, they do not show the appreciable coseismic effects of that earthquake exhibited by other

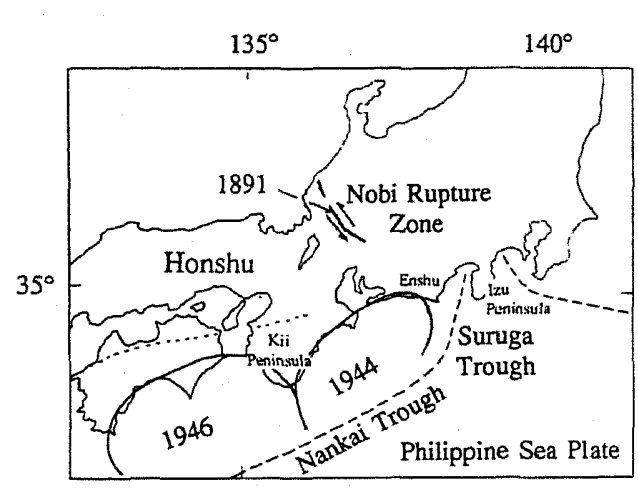

(a)

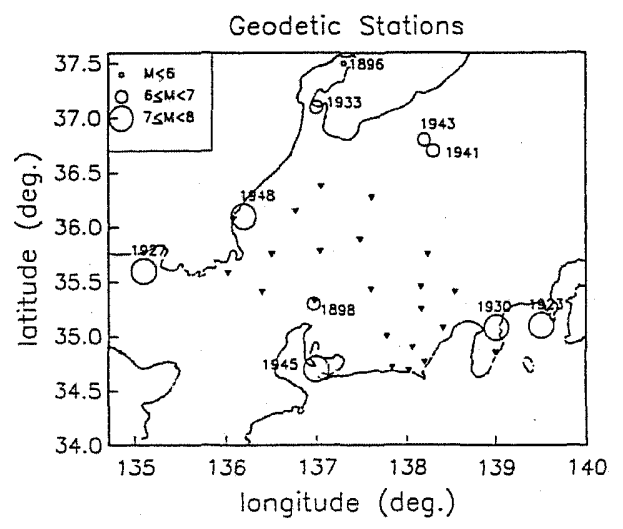

(b)

Fig. 1. (a) Map of Honshu and the Philippine Sea interplate boundary, showing the rupture zones of the 1891 Nobi, 1944 Tonankai, and 1946 Nankaido earthquakes. The Philippine Sea plate is subducting beneath central and south Honshu in the direction $\mathrm{N} 50^{\circ} \mathrm{W}$ at the rate of $4 \mathrm{~cm} /$ year. Modified from Mogi (1981). (b) Subset of 22 geodetic stations employed in this study, shown by inverted triangles. Significant onland earthquakes (Usami, 1979; Kanaori et al., 1992) are superimposed. 


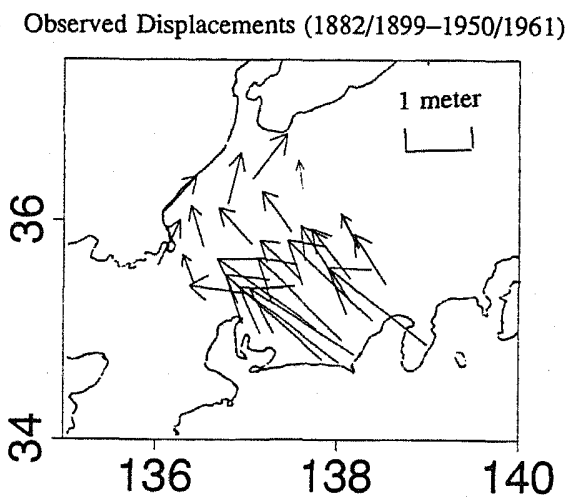

(a)

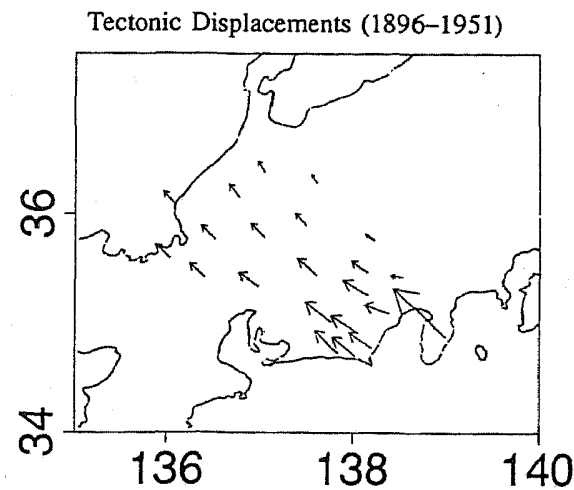

(b)

Fig. 2. (a) Observed horizontal displacement vectors during the period 1882/1899-1950/1961 (Harada and Isawa, 1969). (b) Horizontal displacement vectors predicted for the period 1896-1951 based on a model of tectonic strain accumulation and release. This tectonic model (described later in text) includes the effects of strain accumulation at the Philippine Sea interplate boundary and coseismic offsets associated with the 1944 Tonankai earthquake.

stations to the southwest. Moreover, we shall account for the coseismic effects of the 1944 Tonankai earthquake on the crustal deformation data set when we perform a detailed modelling of the various components of strain accumulation and release along the Philippine Sea interplate boundary. In addition, since we aim to interpret the horizontal displacement data set in terms of postseismic relaxation following the 1891 earthquake, the data vectors have been chosen to lie in districts which were surveyed primarily after the 1891 event, in order to avoid any possible signal from coseismic offsets due to the 1891 event. Those positions which were surveyed before 1891 (district I in figure 12 of Harada, 1967) are far enough from the 1891 rupture zone to not have suffered any appreciable effects from 1891 coseismic offsets.

The displacement vectors reach a magnitude of roughly $1.5 \mathrm{~m}$ near the southern coast and diminish to about $0.5 \mathrm{~m}$ at the northern end of the network. Since the southern coast is closest to the Philippine Sea interplate boundary and the displacements are in the direction away from the trench, the displacement pattern has been traditionally interpreted as reflecting steady state strain accumulation due to Philippine Sea plate subduction beneath central Honshu (Mogi, 1970). In a subsequent section we shall construct a tectonic model which accounts for steady state strain accumulation due to tectonic plate convergence along the Philippine Sea interplate boundary (at a rate of $4 \mathrm{~cm} /$ year), and the coseismic effects of the 1944 Tonankai earthquake (which produced about $4 \mathrm{~m}$ of dip-slip displacement along a considerable portion of the interplate boundary). The predicted displacement field based on this model is shown in Fig. 2(b). It represents the horizontal deformation field corresponding to the same observation points and time interval as the observed displacement field in Fig. 2(a). The tectonic displacement field is only weakly sensitive to the details of the assumed strain 
accumulation geometry, subduction rate, 1944 fault geometry, and 1944 fault slip. Although the displacement field plotted in Fig. 2(b) is nonunique, in the sense that it may be subjected to an arbitrary rigid rotation to allow for comparison with the observed field, it is clear that it poorly reproduces the overall pattern of the observed displacement field. For further details, consult the section "Influence of Tectonic Plate Convergence." This is the primary motivation for investigating the effects of postseismic relaxation following the 1891 earthquake, since these effects are expected to modify the purely tectonic displacement field considerably.

To reinforce the need for considering postseismic effects in the observed data, we point out the nonsymmetrical nature of the displacements about a line coinciding with the Neodani Fault in the northern part of the network. This suggests at least some influence of 1891 Nobi postseismic displacements on the observed displacements; in fact, allowing for an arbitrary translation of the entire displacement field, the pattern of displacements in the northern part of the network grossly resembles that expected for postseismic displacements near a left-lateral strike-slip fault (see, for example, figure 6 of Pollitz, 1992). In addition, while the influence of tectonic strain accumulation along the Philippine Sea plate boundary must be thoroughly explored, we point out that the pattern of displacement observed in the southern part of the network grossly resembles that expected for postseismic displacements near an inland thrust fault located somewhere near the southern terminus of the Umehara Fault (see figure 7 of Pollitz, 1992). The pattern of postseismic displacement near the 1927 Tango earthquake has been interpreted in essentially the same way (Tabei, 1989). In subsequent sections, we shall systematically explore how well the observed displacements may be explained by (1) postseismic relaxation due to faulting associated with the 1891 Nobi earthquake, and (2) tectonic strain accumulation along the Philippine Sea plate boundary.

Based on the fact that none of the observed displacements reflect significant coseismic effects from any earthquake (including the 1891 earthquake), and that the latest observations in the old triangulation were recorded in 1899, we group all old triangulation measurements into an "observation time" of 1896. Similarly, based on the times of the new triangulation in the various districts of Japan (Harada, 1967), we group all new triangulation measurements into an observation time of 1951 . The observed horizontal displacement vectors are then considered to represent the horizontal displacement field in central Honshu between the years 1896 and 1951.

To model the postseismic displacement field due to hypothetical faulting associated with the Nobi earthquake, we must specify a rheological model appropriate for the central Honshu crust and upper mantle. We adopt the model of Table 1, which is shown

Table 1. Earth model.

\begin{tabular}{cccrrr}
\hline Layer & Bottom radius & Top radius & $\mu$ & $\kappa$ & $\eta$ \\
\hline 1 & 3,471 & 6,208 & 13.0 & 25.0 & 1,000 \\
2 & 6,208 & 6,338 & 7.5 & 14.0 & 16 \\
\hline
\end{tabular}

Units of $\mu, \kappa$ are $10^{11} \mathrm{dyne} \cdot \mathrm{cm}^{-2}$. Units of $\eta$ are $10^{18} \mathrm{~Pa} \cdot \mathrm{s}$. Units of radius are $\mathrm{km}$. 


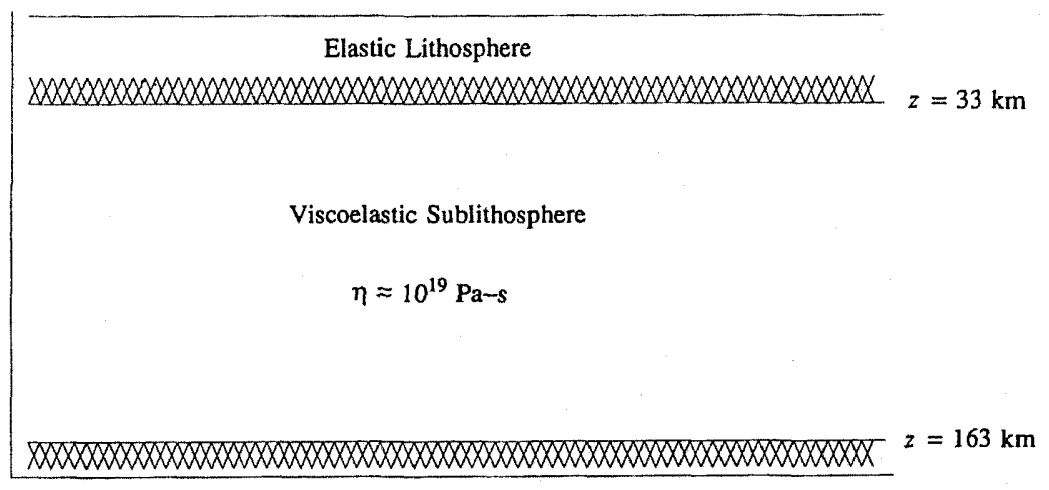

Fig. 3. Rheological model of central Honshu crust and upper mantle, consisting of a $33 \mathrm{~km}$ thick elastic lithosphere above a $130 \mathrm{~km}$ thick viscoelastic sublithosphere (asthenosphere). The elastic parameters and asthenospheric viscosity for this model are listed in Table 1.

in Fig. 3, for this purpose. The adopted elastic plate thickness $H_{\mathrm{e}}=33 \mathrm{~km}$ and Maxwell relaxation time $\tau=2 \eta / \mu=13.5$ year (where $\eta$ is the viscosity and $\mu$ is the rigidity of the viscoelastic sublithosphere) are based on the values obtained by Thatcher et al. (1980) and the Research Group for Explosion Seismology (1977) for northeast Honshu. In Miyashita's (1987) study of the inner zone of southwest Honshu, he determined $H_{\mathrm{e}}=$ $32 \mathrm{~km}$ and $\tau=19.3$ year. Ishida's (1992) depth sections of seismicity show that the dominant microseismic activity in central Japan not associated with plate subduction extends to about $20 \mathrm{~km}$ depth. The effective elastic plate thickness determined by observations of plate flexure (McNutt et al., 1988) are often much higher than the cutoff depth of seismicity. Therefore the ductile lower crust appears to maintain some elastic stress on a long time scale (Cohen, 1981). Cohen (1982) has modelled such a lower lithospheric layer as a standard viscoelastic solid, with a viscosity 20 times that of the asthenosphere. Tabei (1989) determined that the performance of an elastic-viscoelastic coupled model with an elastic upper layer and high viscosity lower crust is nearly identical to the behavior of an elastic upper plus lower crust, allowing for an appropriate change in the asthenospheric viscosity. This is especially true for the period of observation which we consider $(t / \tau \leq 4)$. Therefore we regard the impact of a high viscosity lower crust as inconsequential for our analysis.

Because the observation times of the old and new triangulation in central Honshu are 5 and 60 years, respectively, after the event, we find that there is moderate sensitivity of the calculated horizontal displacement field on the viscosity. The predicted postseismic strain fields would decrease by about $25 \%$ if the viscosity were doubled; this would lead to a corresponding increase in the fault slip estimates, due to the tradeoff between viscosity and fault slip. On the other hand, there is considerable sensitivity of the calculated displacement field on the sublithospheric channel thickness $H_{\text {asth }}$ if $H_{\text {asth }}$ is decreased much below $130 \mathrm{~km}$; for thicknesses $H_{\text {asth }}>130 \mathrm{~km}$ there is little sensitivity because the network aperture is on the order of $150 \mathrm{~km}$. These conclusions are illustrated by figures 7 and 13 of Pollitz (1992), which compare the displacement and strain fields

Vol. 42, No. 1, 1994 


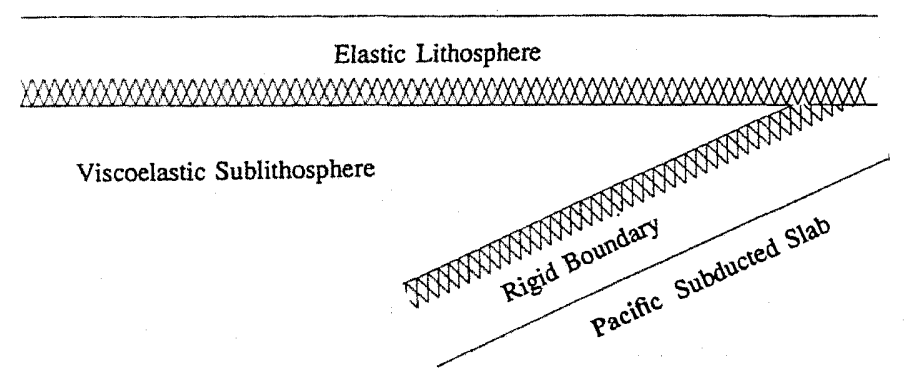

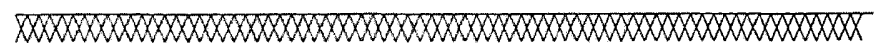

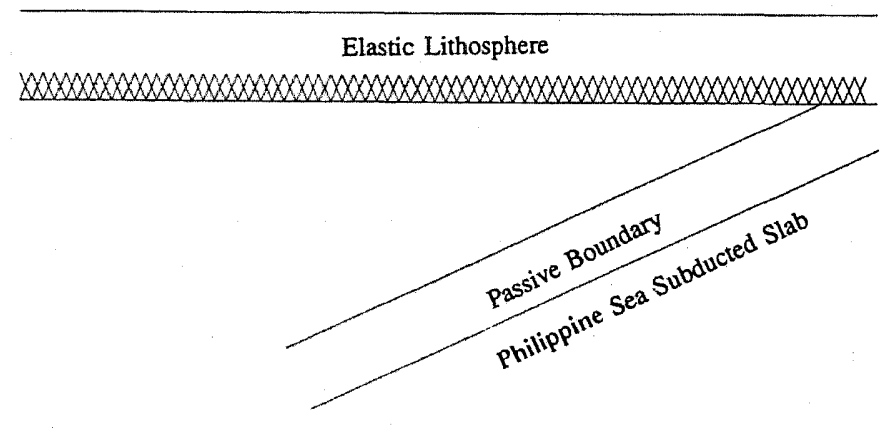

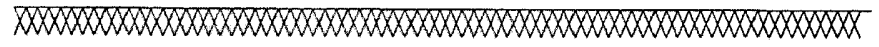

Fig. 4. Two possible alternative models for the behavior of the Philippine Sea subducted slab in the sublithosphere. In (a), the slab acts as a rigid boundary layer, so that displacements from postseismic relaxation must be zero at the upper and lower slab boundaries. In (b), the slab moves passively with the sublithospheric flow, so that the behavior of the sublithosphere is well approximated by a viscoelastic asthenospheric channel of relatively large thickness. Model (a) applies to northeastern Honshu, where relatively old and thick Pacific lithosphere is subducting, whereas model (b) likely applies to central Honshu, where relatively young and thin Philippine Sea lithosphere is subducting.

generated by a thrust fault on an earth model with channel thickness of either $153 \mathrm{~km}$ or $68 \mathrm{~km}$; for observations made 60 years after the earthquake within about $100 \mathrm{~km}$ of the fault, there are considerable differences in the calculated strain field, essentially because displacements are highly attenuated when a small channel thickness exists. The use of $H_{\text {asth }}=130 \mathrm{~km}$ for the channel thickness represents a choice between two possible alternative models for the sublithospheric structure of central Honshu. In the first, shown in Fig. 4(a), the Philippine Sea subducted slab, which has an average depth of $100 \mathrm{~km}$ beneath the study area (or $70 \mathrm{~km}$ beneath the base of the lithosphere), acts as a solid boundary layer and defines the base of the sublithospheric channel. Such a model is appropriate for northeast Honshu because of the relatively large elastic plate thickness 
of the Pacific descending slab (Rydelek and Sacks, 1990). Beneath central Honshu, however, the Philippine Sea descending slab has an elastic plate thickness of only $27 \mathrm{~km}$ (Watts and Talwani, 1974). Ishida (1992) determined a thickness of $30 \mathrm{~km}$ on the basis of seismicity. This suggests an alternative structural model in which the thin subducted portion of the Philippine Sea plate rides passively with the sublithospheric mantle flow (Fig. 4(b)). In this case, the appropriate channel thickness is much greater than $70 \mathrm{~km}$. We have found that the network data is poorly explained by postseismic relaxation effects when a small $(70 \mathrm{~km})$ channel thickness is used, but is satisfactorily explained when a larger channel thickness is used. This result clearly favors the second structural model of sublithospheric structure beneath central Honshu (Fig. 4(b)), and we have therefore chosen a channel thickness of $130 \mathrm{~km}$ for the modelling work performed here. Combined with the assumed viscosity and observation times of the triangulation network, the postseismic displacement fields computed on this model behave nearly like those expected for a completely relaxed earth. For comparison, the Pacific subducted slab has an average depth of about $300 \mathrm{~km}$ beneath the study area (Utsu, 1974).

The displacement field derived from the original triangulation data and shown in Fig. 2(a) is at best a relative displacement field, rather than an absolute displacement field, since it was derived with the assumption of fixed points at various locations (Harada and Isawa, 1969). The change in strain field represented by the displacement vectors, however, may be regarded as the absolute change in strain because of the invariance of strain with respect to rotation or translation of the network. For this reason, we model the angle changes associated with the horizontal displacement field. We construct, in fact, a "triangulation data set" consisting of every angle change among every possible triangle which can be constructed among the 22 stations in the network. The number of triangles is $(22 * 21 * 20) / 3 !=1,540$, so the number of angle changes in the constructed data set is $N=4,620$.

We next address the problem of assigning errors to the newly constructed "triangulation data." This may be accomplished in a grossly approximate fashion by considering the average standard error $\bar{\sigma}_{\text {original }}$ in the original triangulation data, the average angle change $\bar{\gamma}_{\text {original }}$ in the original triangulation, the corresponding average angle change $\bar{\gamma}_{\text {constructed }}$ in the constructed triangulation data, and the number of repeated angle changes $M$ employed in the original triangulation. By treating each angle change in the constructed data set as an independent observation, we obtain a suitable formula for the average standard error $\bar{\sigma}_{\text {constructed }}$ in the constructed triangulation data:

$$
\bar{\sigma}_{\text {constructed }}=\bar{\sigma}_{\text {original }}\left[\frac{\bar{\gamma}_{\text {original }}}{\bar{\gamma}_{\text {constructed }}}\right]\left[\frac{N}{M}\right]^{1 / 2} .
$$

From Harada (1967), the average standard error in the old (1882-1899) triangulation is about $1.0^{\prime \prime}$, and the average standard error in the new (1950-1961) is about $0.6^{\prime \prime}$, so that the average standard error in an angle change is $\bar{\sigma}_{\text {original }}=\left(1.0^{2}+0.6^{2}\right)^{(1 / 2)}=1.17^{\prime \prime}$. We also have $\bar{\gamma}_{\text {original }} \approx 1.8^{\prime \prime}$ and $M \approx 130$ in the original triangulation. We use only rough approximations here for these quantities, derived from the information in Harada (1967) and Harada and Isawa (1969), since their modelling also includes several triangles which were not part of a repeated survey. In the constructed data we have $\bar{\gamma}_{\text {constructed }}=1.16^{\prime \prime}$. 
With $N=4,620$ we then obtain $\bar{\sigma}_{\text {constructed }}=4.7^{\prime \prime}$. This represents simply the standard error which must be assigned to each constructed angle change if they are to be treated as independent (uncorrelated) data.

The constructed angle changes are modelled in terms of postseismic relaxation due to faulting along hypothetical faults associated with the Nobi earthquake. This is done through a least-squares procedure which seeks to minimize the difference $\chi^{2}$ between the data and model angle changes, where

$$
\chi^{2}=\sum_{i=1}^{N} \frac{1}{\bar{\sigma}^{2}}\left[\gamma_{i}^{\mathrm{obs}}-\gamma_{i}^{\mathrm{cal}}\right]^{2},
$$

where $\gamma_{i}^{\text {obs }}$ and $\gamma_{i}^{\text {cal }}$ are the $i$ th data and model angle changes, respectively. More generally, when plate tectonic loading is included in the modelling, the variance $\chi^{2}$ takes the form

$$
\chi^{2}=\sum_{i=1}^{N} \frac{1}{\bar{\sigma}^{2}}\left[\gamma_{i}^{\text {obs }}-\gamma_{i}^{\mathrm{cal}}-\gamma_{i}^{\mathrm{tec}}\right]^{2},
$$

where $\gamma_{i}^{\text {tec }}$ is the change in the $i$ th angle due to plate tectonic strain accumulation within the network.

The calculated angle changes are of the form

$$
\gamma_{i}^{\mathrm{cal}}=\sum_{j} \mu_{j} G_{j i}
$$

where $\mu_{j}$ is the slip on the $j$ th fault segment and $G_{j i}$ is a Frechet derivative representing the change in the $i$ th angle due to unit slip along the $j$ th fault.

Variance reduction is defined according to $V R=1-\chi^{2} / \chi_{0}{ }^{2}$, where $\chi_{0}{ }^{2}$ is the initial variance. A fit of the data at the level of the estimated noise is found to correspond to a variance reduction of $58.5 \%$. The estimated noise level may actually be overestimated because the effect of systematic errors in repeated triangulation surveys could lead to an overestimation of $\bar{\sigma}_{\text {original }}$ (Pollitz and Sacks, 1992). Thus, a higher variance reduction may still be consistent with the presence of unmodelled signal in addition to noise. Without any direct knowledge of possible systematic errors in the original triangulation data, however, we feel that a variance reduction of about $60 \%$ is the maximum we can expect for modelling the deterministic signals in the data.

The inversions of the data set for fault slip are divided into four sets which we shall describe in order of increasing complexity. In the first set (Inversion I), we seek to identify those faults most likely to be associated with the Nobi earthquake. The Nukumi-Neodani and Umehara fault segments associated with the surface rupture during the Nobi event must clearly be included. As remarked earlier, we find that the pattern of vector displacements in the southern part of the network resembles that expected for postseismic relaxation following an inland thrust event which we associate with the Nobi event. Since the size and location of such a hypothetical thrust fault are unknown at the outset, we created several such hypothetical faults and constructed the appropriate Frechet derivatives for them. The fault ruptures of the Nobi event are assumed to extend from the surface (or a specified depth) down to the base of the elastic plate at $H_{\mathrm{e}}=33 \mathrm{~km}$ depth. Since the aim of Inversion $I$ is to identify those faults most 


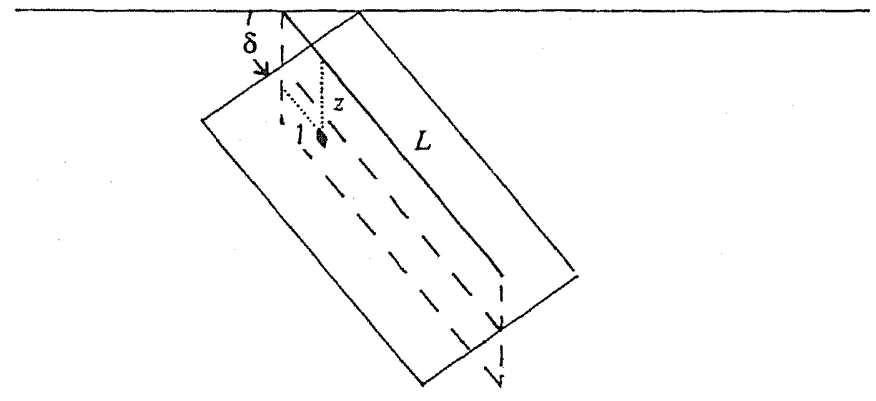

Fig. 5. Fault geometry illustrating the approximation used in deriving Frechet derivatives $G_{i j}$ via Eq. (4) in Inversion I. The vertical fault plane is used to approximate a dipping fault plane of length $L$ and $\operatorname{dip} \delta$. The quantities $l$ and $z$ refer to the integration variables in Eq. (4).

likely associated with rupture during the Nobi earthquake, we employ a simplified fault model in which local point sources are integrated along a vertical plane rather than a dipping plane, in order to approximate faulting along a finite dipping fault plane. More precisely, let $G_{j i}^{\prime}\left(\mathbf{r}_{s}\right)$ be the Green's function for the $i$ th angle change due to a displacement discontinuity at point $\mathbf{r}_{s}$ on the $j$ th fault plane, per unit fault area. Then $G_{j i}$ may be obtained by integration of local point sources along the fault plane:

$$
G_{j i}=\iint G_{j i}^{\prime}\left(\mathbf{r}_{s}\right) \mathrm{d}^{2} \mathbf{r}_{s},
$$

where $\mathrm{d}^{2} \mathbf{r}_{s}$ is the area element along the dipping fault plane. In the approximation adopted in Inversion I, Eq. (5) is replaced with

$$
G_{j i}=\frac{1}{\sin \delta} \int_{0}^{H_{\mathrm{e}}} \mathrm{d} z \int_{0}^{L} \mathrm{~d} l G_{j i}^{\prime}(l, z),
$$

where (Fig. 5) $\delta$ is the fault dip, $z$ is the running depth, $l$ is the running length, and $L$ is the fault length. The geographical location of this simplified vertical fault is taken to be directly above the midpoint line of the equivalent finite dipping fault (Fig. 5). This approximation makes no difference for vertically dipping strike-slip faults but simplifies the computation of $G_{j i}$ considerably for finite dipping thrust faults; this greatly reduces the computation time needed to calculate the $G_{j i}$ for the thrust faults. The Green's functions for displacement due to a point source with a specified moment tensor are computed using the method of Pollitz (1992), which computes the postseismic displacements from an arbitrary point source in a spherical earth geometry. It is then a simple matter to calculate the Frechet derivatives, which is done via Eq. (6) in Inversion I, and via the exact expression (5) in subsequent inversions (Inversions II, III, and IV). 
Table 2. Candidate fault segments used in Inversion I.

\begin{tabular}{ccccccc}
\hline Segment & Type & $\begin{array}{c}\text { Strike } \\
\left({ }^{\circ} \mathrm{CW} / \mathrm{N}\right)\end{array}$ & Dip $\left({ }^{\circ}\right)$ & Length $(\mathrm{km})$ & \multicolumn{2}{c}{ Endpoint* } \\
\hline 1 & Left lateral strike-slip & 120 & 90 & 38 & 35.38 & 137.00 \\
2 & Left lateral strike-slip & 144 & 90 & 51 & 35.54 & 136.67 \\
3 & Thrust & 45 & 45 & 50 & 35.70 & 137.15 \\
4 & Thrust & 45 & 45 & 50 & 35.40 & 137.65 \\
5 & Thrust & 45 & 45 & 50 & 35.08 & 137.26 \\
6 & Thrust & 45 & 45 & 50 & 35.42 & 137.24 \\
\hline
\end{tabular}

* Fault endpoint closest to strike direction.

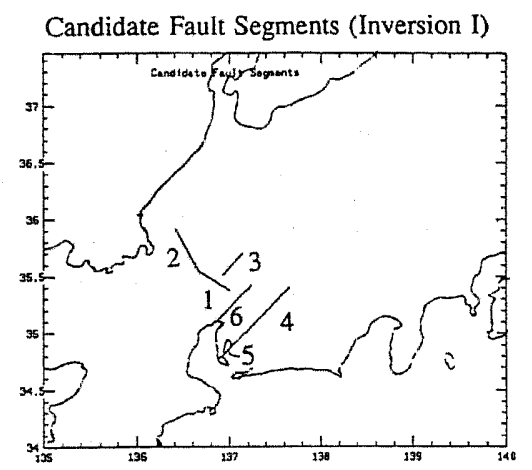

Fig. 6. Line segment sources used as candidate faults for the Nobi earthquake in Inversion I. Each source consists of a vertically dipping fault of width $H_{\mathrm{e}}=33 \mathrm{~km}$ directly below the corresponding line segment, with the fault type listed in Table 2.

\section{Inversion without Correction for Tectonic Effects}

The inversion results presented in this section do not include the effect of tectonic strain accumulation and release. These effects will be considered in a detailed model in the next section. In this section we shall concentrate on identifying the sources of faulting involved in the Nobi earthquake on the basis of the postseismic displacements, and the modelling will enable us to subsequently compare the results obtained without/with tectonic effects.

The faults used in the modelling for Inversion I are listed in Table 2 and are shown in Fig. 6. Faults Nos. 1 and 2 correspond to the Umehara and Nukumi-Neodani faults, respectively, and faults Nos. 3-6 correspond to $45^{\circ}$-dipping thrust faults at various geographic locations near the southern part of the network. These thrust faults have been chosen to have a northeast-southwest trend. This is based primarily on the southeast-northwest direction of subduction of the Philippine Sea plate, but it is also consistent with the geometry of the strike-slip faulting. That is, the same local stress 
Table 3. Results of Inversion I.

\begin{tabular}{crrc}
\hline Segments fitted & Slip* $(\mathrm{m})$ & Error (m) & $\begin{array}{c}\text { Variance } \\
\text { reduction (\%) }\end{array}$ \\
\hline 1 & -5.26 & 1.88 & 11.7 \\
2 & 9.17 & 1.57 & \\
\hline 1 & 1.55 & 1.98 & \\
2 & 8.64 & 1.65 & 54.3 \\
4 & 10.80 & 1.45 & \\
5 & 6.27 & 2.12 & \\
\hline 1 & 1.64 & 2.25 & \\
2 & 7.90 & 1.92 & 56.2 \\
3 & 0.87 & 2.45 & \\
4 & 9.96 & 1.55 & \\
5 & 4.13 & 2.49 & \\
6 & 4.43 & 2.32 & \\
1 & 0.59 & 1.92 & \\
2 & 8.57 & 1.41 & \\
4 & 10.67 & 1.41 & \\
6 & 6.29 & 1.84 & \\
\hline
\end{tabular}

* Left-lateral slip on strike slip faults; reverse slip on thrust faults.

field can plausibly be responsible for causing failure along the strike-slip segments as well as the hypothetical thrust segments. The source of this tectonic stress field is naturally identified as the Philippine Sea interplate boundary. We note that the pattern of observed displacements in the southern part of the network also supports a northeast-southwest trend for the thrust fault(s). By performing inversions with and without these thrust faults, we may test how well the data set is explained by strike-slip faulting alone, as well as deduce the most likely location for thrust faulting associated with the Nobi earthquake.

The results of inversions of the data set using various combinations of the faults are presented in Table 3. From this it is clear that postseismic relaxation following strike-slip faulting alone is incapable of explaining the crustal deformation following the Nobi earthquake, while a model employing both strike-slip faults and an inland thrust fault does an excellent job of explaining the data. The inverted slip distributions point to segments Nos. 4, 5, and 6 as being likely locations for thrust faulting during the Nobi earthquake. Since the inverted slip on segment No. 4 is largest, followed by segment Nos. 5 and 6, we are left to choose between segments Nos. 5 and 6 as being plausible locations of thrust faulting. In the calculations which follow, we shall consider a fault model composed of faults Nos. 1, 2, 4, and 5. Because of the long wavelength nature of postseismic displacements, it is largely inconsequential whether faults No. 5 or No. 6 are adopted. The postseismic displacement vectors based on this model are shown Fig. 7 and are in good agreement in pattern and magnitude with the observed displacement field (Fig. 2(a)). The improvement in variance reduction (from 12 to $54 \%$ ) 
Postseismic Displacements (Inversion I)

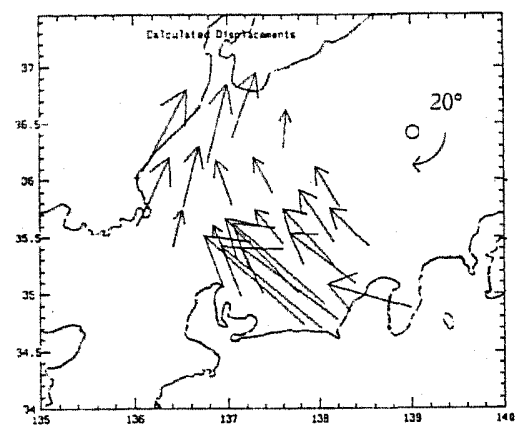

Fig. 7. Calculated Nobi postseismic displacement vectors for the period 18961951 after Inversion I. Note that the calculated vectors have undergone a rotation of $20^{\circ}$ about the point $\left(36.4^{\circ} \mathrm{N}, 139.0^{\circ} \mathrm{E}\right)$; this rotation was determined visually to allow satisfactory comparison with the observed displacement vectors in Fig. 2.

by including an inland thrust fault (segments Nos. 4 and 5), in addition to the strike-slip faults, is impressive and strongly suggests the participation of inland thrust faults during the Nobi earthquake, with several meters of slip.

In Fig. 7 and in several subsequent comparisons with the vector displacement data of Harada and Isawa, we find that a clockwise rotation of $20^{\circ}$ about the point $36.4^{\circ} \mathrm{N}$, $139.0^{\circ} \mathrm{E}$ is necessary to bring the calculated displacement fields into satisfactory agreement with the observed displacement field. Such a rotation is justified because we only seek a model which satisfies the strain field represented by Harada and Isawa's displacement data, and the strain field is invariant with respect to an arbitrary rotation. Therefore, we do not regard Harada and Isawa's data in central Japan as an absolute displacement field but rather a representation of the strain field. Their estimated vector displacement field for all of Japan was obtained by processing triangulation data assuming a number of fixed points, mostly near the Sea of Japan. It is reasonable to assume that a different choice of fixed points could be specified which would bring their absolute displacement field into satisfactory agreement with our calculated displacement fields and remain consistent with the triangulation data in all of Japan. We offer no suggestion for how to respecify the fixed points and only point out that a $20^{\circ}$ rotation is appropriate for the displacement field in central Japan.

In the second phase of inversions (Inversion II), we model postseismic displacements from the thrust faults exactly, using Eq. (5) for the $G_{j i}$. Here we confine attention to the strike-slip faults and the thrust fault segments Nos. 4 and 5 identified as best by Inversion I. The finite fault segments used in Inversion II are specified in Table 4 and are plotted in Fig. 8. In constructing a three-dimensional dipping fault out of segments Nos. 4 and 5 , we have chosen a dip of $45^{\circ}$ towards the northwest. Since horizontal postseismic displacements are not very sensitive to the details of faulting within the upper part of the elastic plate, we assume for the purposes of Inversion II that the thrust fault penetrated the entire elastic plate between 0 and $33 \mathrm{~km}$ depth. 
Table 4. Candidate fault segments used in Inversions II, III.

\begin{tabular}{ccccccc}
\hline Segment & Type & $\begin{array}{c}\text { Strike } \\
\left({ }^{\circ} \mathrm{CW} / \mathrm{N}\right)\end{array}$ & Dip $\left({ }^{\circ}\right)$ & Length $(\mathrm{km})$ & Eat. $\left({ }^{\circ} \mathrm{N}\right)$ & Lon. $\left({ }^{\circ} \mathrm{E}\right)$ \\
\hline 1 & Left lateral strike-slip & 120 & 90 & 38 & 35.38 & 137.00 \\
2 & Left lateral strike-slip & 144 & 90 & 51 & 35.54 & 136.67 \\
4 & Thrust & 225 & 45 & 50 & 35.23 & 137.08 \\
5 & Thrust & 225 & 45 & 50 & 34.91 & 136.69 \\
\hline
\end{tabular}

* Lowermost corner of fault closest to strike direction.

Candidate Fault Segments (Inversion II)

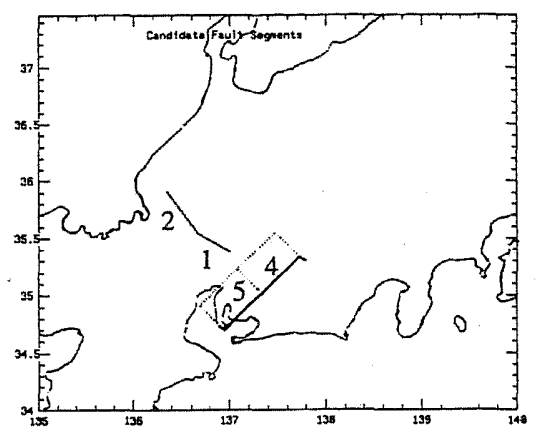

Fig. 8. Candidate finite faults used in Inversion II, with fault parameters listed in Table 4.

Table 5. Results of Inversion II.

\begin{tabular}{cccc}
\hline Segments fitted & Slip* $(\mathrm{m})$ & Error (m) & $\begin{array}{c}\text { Variance } \\
\text { reduction (\%) }\end{array}$ \\
\hline 2 & 8.27 & 1.27 & \\
4 & 9.77 & 1.55 & 51.1 \\
5 & 6.62 & 2.02 & \\
\hline
\end{tabular}

* Left-lateral slip on strike slip faults; reverse slip on thrust faults.

The results of Inversion II are presented in Table 5. We have constrained the segment No. 1 slip to be zero in this inversion because otherwise slightly negative (or right-lateral) slip values are obtained, and we deem these to be physically unrealistic. The northeastern portion (segment No. 4) coincides remarkably with a center of crustal uplift determined between the years 1889 and 1929 by Dambara (1968; his figure 2). The leveling surveys in the vicinity of the northeast thrust were actually conducted in 1902 (old survey) and 1933 (new survey). The pattern of vertical uplift is similar to that obtained for the period $1898-1930$ by Hayashi (1969). This uplift is in the correct 


\section{Postseismic Displacements (Inversion II)}

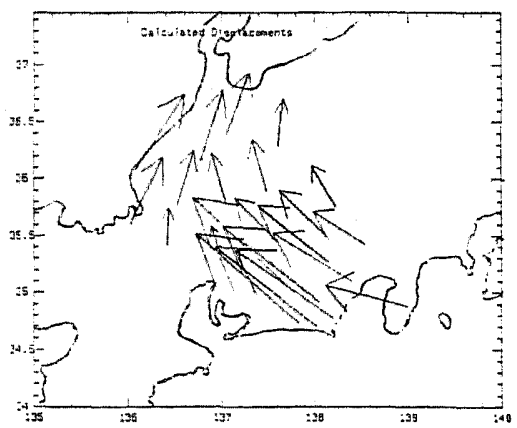

Fig. 9. Calculated Nobi postseismic displacement vectors for the period 1896-1951 after Inversion II. Note that the calculated vectors have undergone a rotation of $20^{\circ}$ about the point $\left(36.4^{\circ} \mathrm{N}, 139.0^{\circ} \mathrm{E}\right)$.

location and of the right sense and magnitude to be associated with postseismic vertical motions due to the participation of the northeast thrust in the Nobi earthquake. The absence of significant uplift in the affected area of the Nobi earthquake during the period 1930-1950 (Hayashi, 1969) and the absense of significant seismicity near segment 4 since 1891, suggests that the uplift observed from $1898-1930$ is due to postseismic relaxation following the slip of segment 4 in 1891 . The only leveling results which could shed light on the coseismic vertical motions associated with the thrust components of the Nobi earthquake have been obtained for partially surveyed lines traversing the southwest thrust from 1885-1894/1985 (Muto and Kawabata, 1933). The lack of relative vertical displacements exceeding $4 \mathrm{~cm}$ south of Nagoya supports the idea of a dominantly deeper slip and more northerly position for the southwest thrust. As discussed in a later section, the leveling data near Nagoya appear to provide direct evidence for a coseismic signal from the southwest thrust fault.

The postseismic displacement vectors according to the fault model of Table 5 are shown in Fig. 9. These again may be compared with the observed displacement vectors of Fig. 2(a) and show good agreement in pattern and magnitude. We may, however, note the consistent misfit (in these and subsequent inversions) of the displacement vector observed at one station at $35.3^{\circ} \mathrm{N}, 137.0^{\circ} \mathrm{E}$; this is attributed to its proximity to the magnitude 6.5 November 11, 1898 earthquake (Kanaori et al., 1992). The magnitude of observed displacement at a second station at $36.1^{\circ} \mathrm{N}, 136.1^{\circ} \mathrm{E}$ is also found to be difficult to fit in the calculated models; this is likely due to its proximity to the 1948 Fukui earthquake. Referring to Fig. 1(b), three other earthquakes may be mentioned here. The magnitude 7.1 1945 Mikawa earthquake occurred in eastern Ise Bay but is about $60 \mathrm{~km}$ from the nearest geodetic station. This earthquake produced visible rupture on a short, steeply-dipping fault with dominantly dip-slip motion (Tsuya, 1946) but has an overall strike-slip focal mechanism (Ichikawa, 1971). Because of its large distance from the nearest geodetic station, its effects are negligible even in the case that it accommodated $1 \mathrm{~m}$ of horizontal displacement. The magnitude $7.0 \mathrm{Kiza}-\mathrm{Izu}$ earthquake of the northern Izu Peninsula produced a $20-\mathrm{km}$-long rupture along a nearly north-south 
trending fault, with maximum horizontal slip of about $3.5 \mathrm{~m}$ in the left-lateral sense (Otuka, 1933; Matsuda, 1972). The southern tip of the fault is about $15 \mathrm{~km}$ north of the geodetic station on the Izu Peninsula (Fig. 1(b)). Taking liberal estimates of $3 \mathrm{~m}$ uniform left lateral slip between 0 and $20 \mathrm{~km}$ depth, and an angle of $10^{\circ}$ of the fault plane with respect to the line connecting it with the geodetic station on the Izu Peninsula, the calculated coseismic horizontal offset is $10 \mathrm{~cm}$ in the north-northwest direction. This offset is much smaller than the other effects modelled in this study. Finally, the small displacements in the Izu Peninsula due to the 1923 Kanto earthquake (Ando, 1974) indicate that the 1923 earthquake did not have a significant effect on the horizontal motions observed there.

\section{Influence of Tectonic Plate Convergence}

It is highly important to explore the influence of tectonic strain accumulation on the observed data. The signal from this is expected to be dominated by the subduction of the Philippine Sea plate beneath Honshu (Fig. 1). We shall construct a model of strain accumulation and strain release that may be used to correct the observed data using Eq. (3), and to invert for slip distributions along the inland faults after this correction. It is also important to demonstrate that those effects associated directly with the convergent plate boundary are incapable of explaining Harada and Isawa's geodetic data in central Japan. Although this goes against the traditional interpretation (Mogi, 1970), our quantitative investigation of this issue will firmly clarify the problems which surround the interpretation of this data.

The Philippine Sea plate is subducting beneath central and southern Honshu along the Nankai Trough and Suruga Trough at the rate of about $4 \mathrm{~cm} /$ year in the northwest direction (Seno et al., 1993; Yoshioka et al., 1993). Over the 55-year period of the triangulation network (1896-1951), this will lead to the equivalent of $220 \mathrm{~cm}$ of accumulated slip along the interplate boundary, which is only $50-100 \mathrm{~km}$ south of the southern part of the network. In addition, we must account for the coseismic offsets of all earthquakes occurring between 1896 and 1951 and correct the data set for these as well. By far the most significant earthquake occurring during this time period, in terms of its effects on central Honshu, was the 1944 Tonankai earthquake (Fig. 1). This earthquake ruptured a roughly $200-\mathrm{km}$ length of the interplate boundary (Nankai Trough and Suruga Trough) and is associated with $4 \mathrm{~m}$ of dominantly reverse slip along the subduction zone (Ishibashi, 1981). It is important to include both tectonic strain accumulation and 1944 coseismic offsets in the correction of the data set because the two processes work in opposite directions-the 1944 earthquake released a large fraction of the strain energy accumulated between 1896 and 1951. We now describe the framework for modelling these two processes.

All calculations of coseismic displacements are done using the method of Okada (1985), assigning a value of 0.2662 to Poisson's ratio (derived from layer 3 of Table 1 ). The application of Okada's method assumes a homogeneous earth with elastic parameters equal to those of the crustal layer. This is an excellent approximation if the faulting is confined to the crustal layer, but up to $25 \%$ error may result if faulting extends significantly below the crust (Yoshioka et al., 1989). Since the 1944 rupture is

Vol. 42, No. 1, 1994 
Table 6. Fault and slip geometry of 1944 Tonankai earthquake.

\begin{tabular}{cccccccccc}
\hline Segment & $\begin{array}{c}\text { Strike } \\
\left({ }^{\circ} \mathrm{C} \mathrm{W} / \mathrm{N}\right)\end{array}$ & $\begin{array}{c}\text { Dip } \\
\left({ }^{\circ}\right)\end{array}$ & $\begin{array}{c}\text { Length } \\
(\mathrm{km})\end{array}$ & $\begin{array}{c}D_{\min }^{*} \\
(\mathrm{~km})\end{array}$ & $\begin{array}{c}D_{\max }^{*} \\
(\mathrm{~km})\end{array}$ & $\begin{array}{c}\text { Rake } \\
\left({ }^{\circ}\right)\end{array}$ & $\begin{array}{c}\text { Slip } \\
(\mathrm{m})\end{array}$ & \multicolumn{2}{c}{ Endpoint** } \\
\hline Lat $\left({ }^{\circ} \mathrm{N}\right)$ & Lon $\left({ }^{\circ} \mathrm{E}\right)$ \\
\hline $\mathrm{A}$ & 245 & 24 & 110 & 3.0 & 31.5 & 113 & 4.0 & 33.80 & 135.88 \\
$\mathrm{~B}_{1}$ & 245 & 24 & 40 & 20.0 & 52.5 & 113 & 4.0 & .34 .00 & 137.05 \\
$\mathrm{~B}_{2}$ & 245 & 24 & 40 & 20.0 & 52.5 & 113 & - & 34.15 & 137.39 \\
\hline
\end{tabular}

* $D_{\min }$ and $D_{\max }$ are, respectively, the minimum and maximum depths of slip along the fault plane.

** Lowermost corner of fault at $33 \mathrm{~km}$ depth closest to strike direction.

Table 7. Fault geometry and slip accumulation model between 1896 and 1951.

\begin{tabular}{cccccccccc}
\hline Segment & $\begin{array}{c}\text { Strike } \\
\left({ }^{\circ} \mathrm{CW} / \mathrm{N}\right)\end{array}$ & $\begin{array}{c}\text { Dip } \\
\left({ }^{\circ}\right)\end{array}$ & $\begin{array}{c}\text { Length } \\
(\mathrm{km})\end{array}$ & $\begin{array}{c}D_{\min }^{*} \\
(\mathrm{~km})\end{array}$ & $\begin{array}{c}D_{\max }^{*} \\
(\mathrm{~km})\end{array}$ & $\begin{array}{c}\text { Rake } \\
\left({ }^{\circ}\right)\end{array}$ & $\begin{array}{c}\text { Slip } \\
\text { accumulation }\end{array}$ & \multicolumn{2}{c}{ Endpoint** } \\
\hline $\mathrm{m})$
\end{tabular}

* $D_{\min }$ and $D_{\max }$ are, respectively, the minimum and maximum depths of slip along the fault plane.

** Lowermost corner of fault at $33 \mathrm{~km}$ depth closest to strike direction.

thought to penetrate to a depth of $50 \mathrm{~km}$, minor errors in the calculation of coseismic offsets may result. In our case, however, the displacements are evaluated far from the trench axis, and then the assumption of a homogeneous structural model is a very good approximation (figure 7 of Yoshioka et al., 1989).

Since the 1944 rupture zone is so broad, attention may be confined to strain accumulation along the 1944 rupture planes and their updip (and downdip) extensions. We employ a modified version of the fault model of Ishibashi (1977) for the 1944 event (Table 6 and Fig. 10, left). Note that his "northeast" fault has been divided into two faults, $B_{1}$ and $B_{2}$. We have done this because we believe that the coseismic uplift data is satisfactorily explained with faults $A$ and $B_{1} ; B_{2}$ is only necessary to explain the uplifts observed along the Enshu Coast, but these are possibly not associated with the 1944 event (Ishibashi, 1981). In an effort to improve the modelling of the 1944 earthquake we also consider the possibility of slip along the Suruga Trough during the 1944 event. Ishibashi (1981) has delineated the likely fault geometry of a Suruga Trough fault which participated in the 1854 Ansei earthquake. The surface trace of this fault coincides with the Suruga Trough, and the fault dips towards the west-northwest with a $34^{\circ}$ dip. After considering a variety of slip models involving slip along the Suruga Trough fault plane at various depths, and attempting to fit the data set of vertical uplifts compiled by Sato and Inouchi (1975), particularly the Enshu Coast uplifts, we conclude that no significant slip along this fault could have accompanied the 1944 event. This conclusion has also been reached independently by Ishibashi (1981). On the other hand, since this fault was active during the 1854 earthquake, we consider the possibility 
1944 Fault Geometry

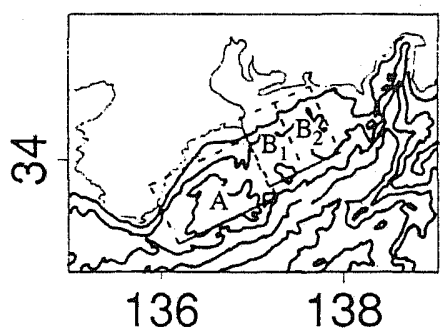

Slip Accumulation Fault Geometry

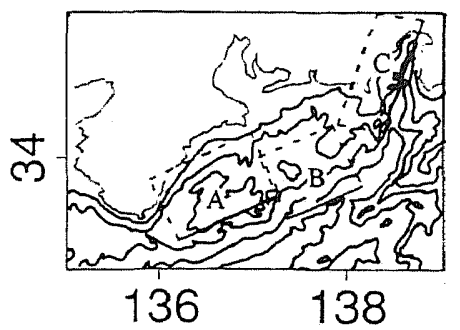

Fig. 10. Left: Fault geometry of the 1944 Tonankai earthquake. The fault parameters of segments $A, B_{1}$, and $B_{2}$, and the slip parameters are listed in Table 6. Right: Fault geometry of tectonic slip accumulation along the Philippine Sea interplate boundary. The fault parameters and total slip values resolved along the fault planes during the period 1896-1951 are listed in Table 7.

that strain accumulation during the interseismic period may involve the Suruga Trough Fault as well as the faults $A$ and $B_{1}$ (which participated in the 1944 event) and $B_{2}$.

Table 7 lists the fault geometry and slip parameters for modelling the strain accumulation between the years 1896 and 1951; these fault planes are plotted in Fig. 10 , right. Fault plane $B$ in Table 7 is equivalent to the updip extension of fault planes $B_{1}+B_{2}$ in Table 6 . To allow for the possibility of strain accumulation at both shallow and greater depths along the various fault planes during the period 1896-1951, we model the tectonic strain accumulation as involving the updip (and downdip) extensions of the 1944 fault planes A and B, as well as the Suruga Trough Fault (plane C), within the entire depth range $3-52.5 \mathrm{~km}$. This spans the entire depth range of slip associated with the 1944 earthquake (Table 6). The slip geometry (rake of fault-parallel slip accumulation) is also taken to be identical to the 1944 slip geometry along planes A and $\mathrm{B}$, and to the 1854 slip geometry along plane $\mathrm{C}$. We wish to emphasize, however, that because of the presence of viscoelastic asthenosphere below $33 \mathrm{~km}$ depth, no tectonic strain accumulation is recorded in the upper plate due to interplate boundary interactions below a depth of $33 \mathrm{~km}$ in the steady state limit. If the rocks at depth had sufficient yield strength, then, in the steady state limit, a time-invariant flow field would be established in the sublithospheric asthenosphere, and no strain accumulation would occur in the upper elastic plate. This insensitivity of the elastic plate (lithosphere) to long-term sublithospheric interactions has also been pointed out by King et al. (1988) and Matsu'ura and Sato (1989). Because of the high strain rate in the flow, however, the yield strength of the sublithospheric rocks is exceeded roughly every 100 years, leading to great interplate earthquakes which penetrate below the base of the elastic plate. These earthquakes and their transient postseismic signals episodically interrupt the steady state flow pattern described above.

This model of strain accumulation is strictly valid provided that we include the effects of coseismic offsets of all earthquakes involving the interplate boundary, as well as their transient postseismic signals. The last historic great earthquake in the Tonankai region prior to the 1944 earthquake was the 1854 Ansei earthquake. In the next set of 
inversions (Inversion III), we shall ignore both the 1944-1951 postseismic displacements due to the 1944 earthquake, as well as the 1896-1951 postseismic displacements due to the 1854 earthquake. In subsequent inversions (Inversion IV) we shall include the effects of the 1854 earthquake. In both sets of inversions, the tectonic model includes: (1) steady state tectonic strain accumulation between the years 1896 and 1951 along the updip and downdip extensions of the 1944 rupture zone (planes A and B) and the Suruga Trough (plane C) between 3 and $33 \mathrm{~km}$ depth, and (2). tectonic strain release-coseismic offsets from the 1944 earthquake. In case (1), the slip rate imposed on planes $A$ and $B$ is $4 \mathrm{~cm} /$ year, and that imposed on plane $C$ is variable and will be denoted by $v$.

The steady state subduction of the Philippine Sea plate is modelled by imposing stick-slip behavior along the elastically coupled downgoing and overriding plates. The subducting oceanic plate essentially drags the thin overriding continental plate with it, and only coupling interactions between the elastic plates are important-sublithospheric interactions are zero in the steady state limit. The calculation uses the method of Rundle (1986) for the steady state motion of two elastic blocks which share a non-slipping area. The downgoing plate is considered to be a conveyor belt travelling horizontally sufficiently far from the trench, and dipping $24^{\circ}$ (or $34^{\circ}$ ) landward of the Nankai Trough (or Suruga Trough). In the steady state, shear stresses are imposed along the non-slipping elastically coupled boundary by imposing a compensating backslip, as explained schematically in figure 4 of Yoshioka et al. (1993). As in previous studies, this method does not address the mechanism by which the normal force on the interplate fault plane is balanced; presumably this is accomplished by the negative bouyancy of the subducted slab. The boundary conditions as specified in this way are nearly identical to those employed in numerical studies (Scholtz and Kato, 1978; Miyashita, 1987; Yoshioka, 1991; Yoshioka et al., 1993). Our method is three-dimensional in both the coupling geometry and the distribution of back-slip along the coupled portions. This allows the possibility of specifying partially rather than completely coupled areas, although in our application we specify complete coupling between 3 and $33 \mathrm{~km}$ depth. The imposition of backslip in the steady state requires (a) the calculation of surface coseismic offsets from a specified displacement discontinuity, and (b) the calculation of surface displacements due to complete relaxation of the asthenosphere. Part (a) is accomplished using the method of Okada (1985). Part (b) is done using the method of Pollitz (1992). Since Okada's method in (a) assumes a homogeneous earth, the relaxation calculation in (b) also employs homogeneous elastic parameters. This approach is valid because, in the steady state, the displacement fields are only sensitive to the structure of the crustal layer. The only approximation involved is, as in all such studies, that the boundaries between the "moving" and "stationary" blocks are unspecified outside of the chosen coupling regions (segments $\mathrm{A}, \mathrm{B}$, and $\mathrm{C}$ ).

We have calculated the displacement vectors for several possible cases of plate convergence and 1944 earthquake slip, spanning all scenarios which we consider conceivable. The vectors for several cases are plotted in Fig. 11; each figure gives the corresponding variance reduction with respect to Harada and Isawa's data set, defined according to Eq. (3). Postseismic displacements from the 1891 earthquake are not included $\left(\gamma_{i}^{\text {cal }}=0\right)$. The top left panel is identical to Fig. 2(a). In all cases, the variance 

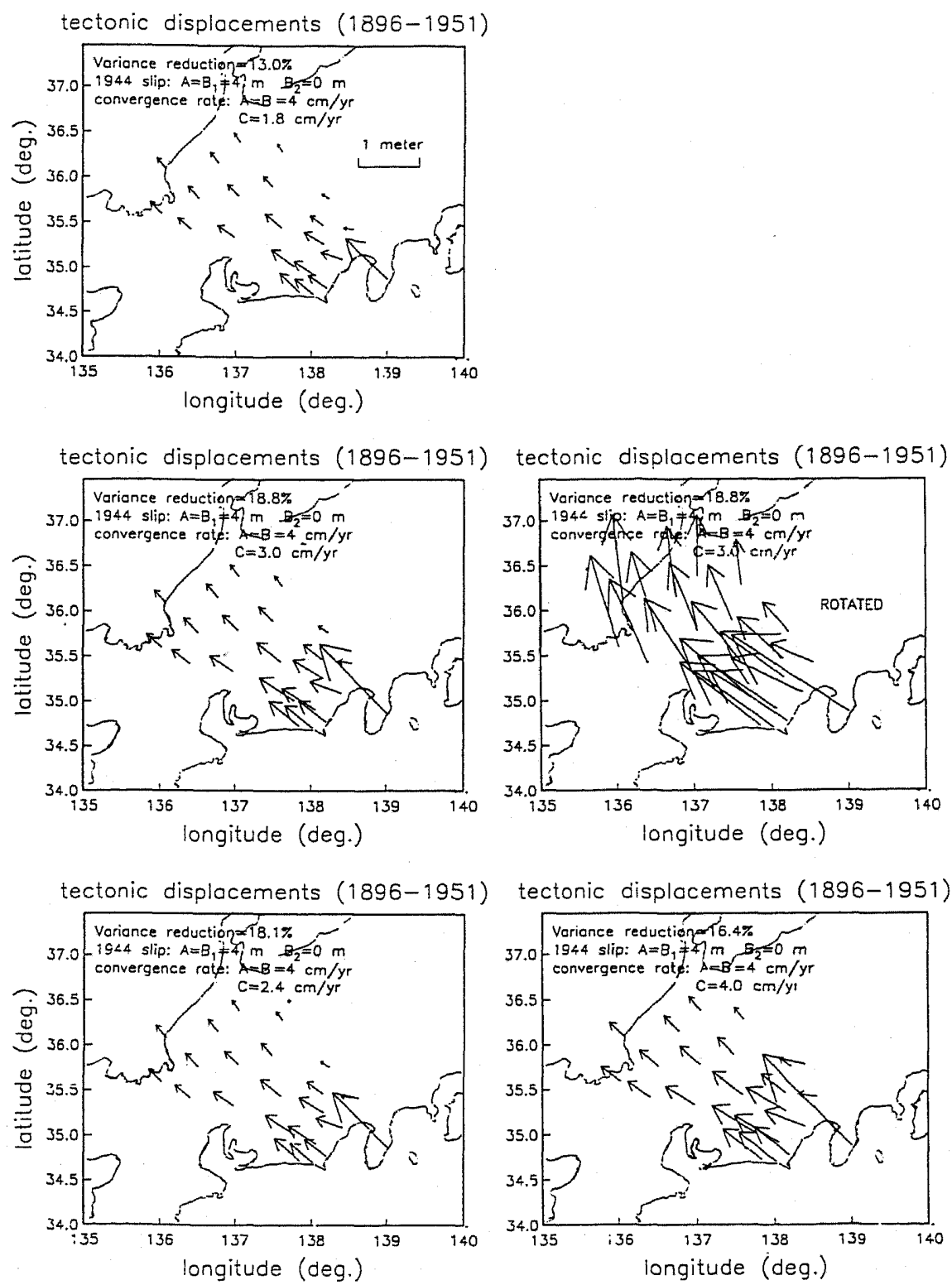

Fig. 11. Calculated horizontal displacement vectors for the period 1896-1951, obtained as the sum of 1944 coseismic displacements and displacement of the overriding continental and subducting oceanic plates from steady state Philippine Sea plate convergence. The corresponding variance reduction with respect to Harada and Isawa's data are indicated. Various combinations of 1944 fault slip (on segments $A, B_{1}$, and $B_{2}$ ) and the rate of interplate convergence (segment $\mathrm{C}$ ) are considered. In these figures the interplate convergence rate on segments $A$ and $B$ is fixed at $4 \mathrm{~cm} /$ year.

Vol. 42, No. 1, 1994 


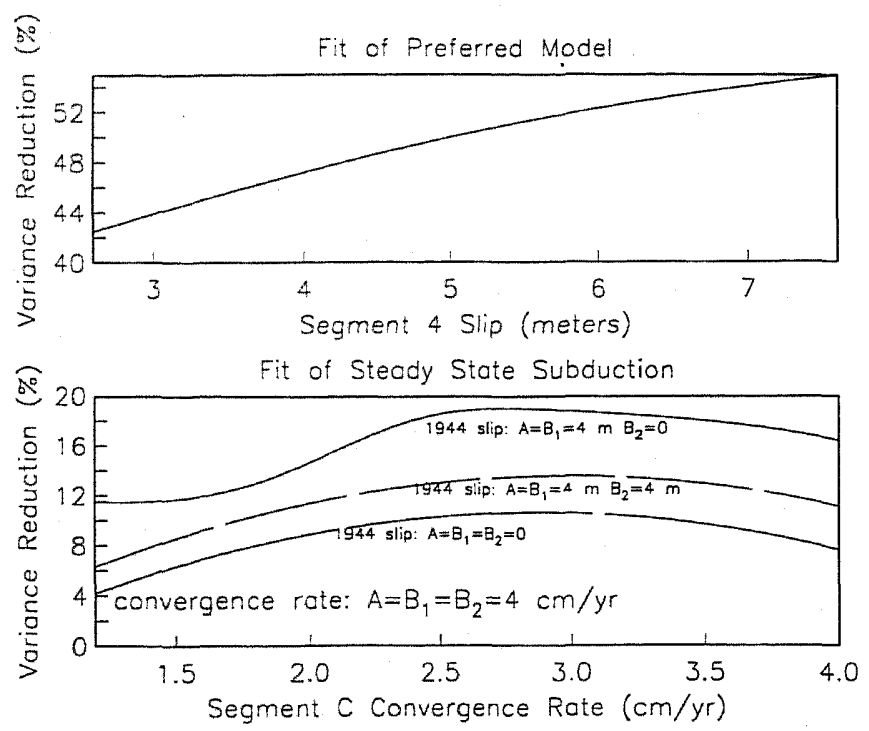

Fig. 12. Top: Variance reduction obtained by the Preferred Model (explained in text) as a function of segment 4 slip during the 1891 earthquake, from forward modelling in the framework of Inversion IV. Bottom: Variance reduction of various strain accumulation and release models with respect to Harada and Isawa's data set. Three different cases of 1944 fault slip are shown. The interplate convergence rate along segment $\mathrm{C}$ is allowed to vary while the convergence rate along segments $A$ and $B$ is fixed at $4 \mathrm{~cm} /$ year.

reduction is unacceptably low. By comparing these figures with the observed displacement vectors in Fig. 2(a), the primary reason for the misfit is the gradual, rather than sharp fall off in calculated displacement as one moves northwestward from the Suruga Trough. Physically, this occurs because the interplate boundary is coupled down to $33 \mathrm{~km}$ depth-equivalent to about $50 \mathrm{~km}$ laterally inland from the Suruga Trough. In spite of the large magnitude of displacement for the eastern Suruga Trough obtained for some of the cases, we find that the fit is only slightly improved by discarding this station. In the top right panel, we subjected the displacement field for the best case to a $20^{\circ}$ rotation to produce better visual agreement with the observed displacement field. Although the two patterns are grossly similar, the variance reduction in terms of dimensionless strain is only $18.8 \%$. All of the cases shown in Fig. 11 assume that, in the 1944 earthquake, segments $A$ and $B_{1}$ ruptured with $4 \mathrm{~m}$ of slip. We tried several other cases involving various combinations of slip for segments $A, B_{1}$, and $B_{2}$ in the 1944 earthquake. The variance reduction curves plotted in Fig. 12 summarize these results. In not one case does the variance reduction with respect to Harada and Isawa's data exceed $19 \%$.

In an effort to improve the fit, we tried changing the minimum and maximum depths of coupling. Several authors have advocated partially or completely decoupled regions at various levels along the interplate boundary (Scholtz and Kato, 1978; 
Miyashita, 1987; Yoshioka, 1991; Yoshioka et al., 1993). In particular, Yoshioka et al. (1993) employ an interplate coupling model for the Nankai Trough and Suruga Trough involving coupling in the depth range $10-30 \mathrm{~km}$, with a decoupled zone from $0-10 \mathrm{~km}$ depth. We tried this coupling model and found no improvement in the variance reduction with respect to the results in Fig. 12. It effectively shifts the variance reduction curves to the right because of the decrease in total coupling area. Reducing the maximum depth of coupling to shallower than $30 \mathrm{~km}$ succeeds in concentrating the deformation near the western Suruga Trough, as is observed, but then the calculated displacements are far too small. The only remaining possibility is that significant coupling interactions extend below $33 \mathrm{~km}$ depth. In the short-term, strain accumulation seems to extend down as far as $50 \mathrm{~km}$ because of the inferred depth of faulting of the 1944 earthquake (Ishibashi, 1981) and present seismicity (Ishida, 1992). In the long-term, however, it is virtually certain that ductile flow dominates the rheology below $33 \mathrm{~km}$ depth. Yoshioka et al. (1993) argue that a mantle wedge of the type inferred by Hashimoto (1984) for the Hokkaido corner, extending to about $60 \mathrm{~km}$ depth, does not appear justified for the subduction in the Suruga Trough. The presence of shallow asthenosphere and the absence of a mantle wedge means that, regardless of the short-term interactions, steady state interactions only extend to about $33 \mathrm{~km}$ depth.

Up against these results, it is very difficult to maintain the traditional view, which was only suggested qualitatively by Mogi (1970) but never justified quantitatively. Unless an alternative explanation is found, the best working hypothesis is that Harada and Isawa's data in central Japan are dominated by postseismic relaxation following the Nobi earthquake.

\section{Inversion with Correction for Tectonic Effects}

The components of tectonic strain accumulation and release have been calculated and summed to form a set of angle changes $\gamma_{i}^{\text {tec }}$ due to tectonic activity. Several inversions (Inversion III) of the data set are performed using Eq. (3) as the data variance function. The fault geometry of the inland faults is identical to that employed in Inversion II (Table 4). As before, we invert for the 1891 slip along the inland faults. These slip distributions, as well as the variance reduction obtained in the inversions, are found to be very sensitive to the slip value of fault plane $B_{2}$ during the 1944 earthquake. This is because of the proximity of the southern network stations to the upward projection of the deeper slip components of this fault. The inversions provide a test of whether the data set is better fit with or without 1944 coseismic offsets along segment $\mathbf{B}_{2}$.

The results of Inversion III are listed in Table 8. The first three of these inversions assign $4 \mathrm{~m}$ of slip to segment $\mathrm{B}_{2}$ during the 1944 event; the last three assign zero slip to segment $\mathrm{B}_{2}$. A model which includes only tectonic strain accumulation and release, and postseismic relaxation from the strike-slip components of the Nobi earthquake, also yields a poor fit ( $25 \%$ variance reduction). Considering the first three inversions, the model which resolves all of the tectonic slip rate of $v=4 \mathrm{~cm} /$ year along the Suruga Trough Fault provides a fair fit of the data, at $43 \%$ variance reduction. A more improved fit and more uniform slip distribution along the inland thrusts is achieved by ignoring tectonic strain accumulation along the Suruga Trough Fault, but this is in conflict with

Vol. 42, No. 1, 1994 
Table 8. Results of Inversion III.

\begin{tabular}{|c|c|c|c|c|}
\hline $\begin{array}{l}\text { Fault planes included for } \\
\text { strain accumulation* }\end{array}$ & Segments fitted & Slip* (m) & Error $(\mathrm{m})$ & $\begin{array}{c}\text { Variance reduction } \\
(\%)\end{array}$ \\
\hline A & 2 & 6.79 & 1.27 & \multirow{4}{*}{52.7} \\
\hline B & 4 & 6.03 & 1.55 & \\
\hline $\mathrm{C}(1.8 \mathrm{~cm} /$ year $)$ & 5 & 8.82 & 2.02 & \\
\hline $\mathrm{B}_{2}^{* *}(4.0 \mathrm{~m})$ & & & & \\
\hline A & 2 & 6.05 & 1.27 & \multirow{4}{*}{42.8} \\
\hline B & 4 & 3.66 & 1.55 & \\
\hline $\mathrm{C}(4.0 \mathrm{~cm} /$ year $)$ & 5 & 9.00 & 2.02 & \\
\hline $\mathrm{B}_{2}(4.0 \mathrm{~m})$ & & & & \\
\hline A & 2 & 7.39 & 1.27 & \multirow{4}{*}{45.9} \\
\hline B & 4 & 7.96 & 1.55 & \\
\hline & 5 & 8.67 & 2.02 & \\
\hline $\mathrm{B}_{2}(4.0 \mathrm{~m})$ & & & & \\
\hline A & 2 & 7.61 & 1.27 & \multirow{4}{*}{54.2} \\
\hline B & 4 & 7.71 & 1.55 & \\
\hline$C(1.8 \mathrm{~cm} /$ year $)$ & 5 & 6.55 & 2.02 & \\
\hline $\mathrm{B}_{2}(0.0 \mathrm{~m})$ & & & & \\
\hline A & 2 & 8.21 & 1.27 & \multirow{4}{*}{47.6} \\
\hline B & 4 & 9.64 & 1.55 & \\
\hline & 5 & 6.46 & 2.02 & \\
\hline $\mathrm{B}_{2}(0.0 \mathrm{~m})$ & & & & \\
\hline A & 1 & -4.26 & 1.86 & \multirow{4}{*}{25.4} \\
\hline B & 2 & 8.31 & 1.63 & \\
\hline$C(4.0 \mathrm{~cm} /$ year $)$ & & & & \\
\hline $\mathrm{B}_{2}(0.0 \mathrm{~m})$ & & & & \\
\hline
\end{tabular}

* Strain accumulation along given fault planes, according to model of Table 7, included in $\gamma_{i}^{\text {tec }}$.

** Coseismic offset of fault plane $B_{2}$ during 1944 earthquake. All inversions include the effect of coseismic offset of fault planes $A$ and $B_{1}$ during the 1944 event.

clear evidence of significant strain accumulation along the trough since at least 1900 (Ishibashi, 1981). Considering all of the cases, it is clear from Table 8 that the data set is best explained by hypothesizing that segment $B_{2}$ did not participate in the 1944 earthquake, and that the slip accumulation rate along the Suruga Trough Fault is $v=1.8 \mathrm{~cm} /$ year.

This estimate is consistent with the average $5 \mathrm{~mm} /$ year depression of western Suruga Bay relative to eastern Suruga Bay since 1900 (Ishibashi, 1981), which agrees with the differential subsidence rates from 1972-1984 determined by Yoshioka et al. (1993). This result is derived from calculation of the steady state strain accumulation from the segment $\mathrm{C}$ component of Table 7 using $v=1.8 \mathrm{~cm} /$ year. It must be noted, however, that this estimate is smaller than the $3 \mathrm{~cm} /$ year determined by VLBI data (Matsuzaka et al., 1991) and recent triangulation data (Yoshioka et al., 1993). The reason for this 
Table 9. Results of Inversion IV ${ }^{t}$.

\begin{tabular}{ccccc}
\hline $\begin{array}{c}\text { Fault planes included for } \\
\text { strain accumulation* }\end{array}$ & Segments fitted & Slip* $^{*}(\mathrm{~m})$ & Error $(\mathrm{m})$ & $\begin{array}{c}\text { Variance reduction } \\
(\%)\end{array}$ \\
\hline $\mathrm{A}$ & 2 & 7.62 & 1.27 & \\
$\mathrm{~B}$ & 4 & 7.60 & 1.55 & 60.3 \\
$\mathrm{C}(1.8 \mathrm{~cm} /$ year $)$ & 5 & 6.72 & 2.02 & \\
$\mathrm{~B}_{2}^{* *}(0.0 \mathrm{~m})$ & & & & \\
\hline $\mathrm{A}$ & 2 & 6.88 & 1.27 & 50.3 \\
$\mathrm{~B}$ & 4 & 5.24 & 1.55 & \\
$\mathrm{C}(4.0 \mathrm{~cm} /$ year $)$ & 5 & 6.90 & 2.02 & \\
$\mathrm{~B}_{2}(0.0 \mathrm{~m})$ & & & & \\
$\mathrm{A}$ & 2 & 6.80 & 1.27 & \\
$\mathrm{~B}$ & 4 & 5.92 & 1.55 & \\
$\mathrm{C}(1.8 \mathrm{~cm} /$ year $)$ & 5 & 8.99 & 2.02 & \\
$\mathrm{~B}_{2}(4.0 \mathrm{~m})$ & & & & \\
\hline
\end{tabular}

${ }^{t}$ Includes correction for postseismic relaxation following the 1854 earthquake. * Strain accumulation along given fault planes, according to model of Table 7, included in $\gamma_{i}^{\text {tec }}$. ** Coseismic offset of fault plane $\mathrm{B}_{2}$ during 1944 earthquake. All inversions include the effect of coseismic offset of fault planes $A$ and $\mathbf{B}_{1}$ during the 1944 event.

discrepancy appears to be differences in the degree of coupling between the Philippine Sea plate and the overriding plate, which were specified along the entire depth range $3-33 \mathrm{~km}$ in Table 7. Previous studies of subduction along the southwest Nankai Trough (Miyashita, 1987; Yoshioka, 1991), Suruga Trough (Yoshioka et al., 1993) and Sagami Trough (Scholtz and Kato, 1978) have favored partially or completely decoupled zones at depth because the deeper part of the contact between the two elastic plates has often been inferred to slip aseismically during interseismic periods. If the effective coupling area were reduced in this way, then our estimate of $v$ would correspondingly increase. Yoshioka et al. (1993) found that inferred back-slip rates (which are proportional to v) exhibit a strong dependence on the model of interplate coupling, enough to change the estimate of $v$ by as much as $1 \mathrm{~cm} /$ year depending on the coupling model.

In an effort to improve the modelling even more, we explore the influence of postseismic effects of the 1854 earthquake. All of the network stations located near the Suruga Trough were surveyed before the Nobi earthquake in the old triangulation, and therefore the network would have recorded postseismic motions from the 1854 earthquake between the years $\approx 1889-1951$. We performed additional inversions (Inversion IV) which include these postseismic effects, employing the 1854 fault model of Ishibashi (1981), which essentially prescribes $4 \mathrm{~m}$ of slip along the shallow updip extensions of faults B and C (as well as the rest of the Nankai Trough further south). The results are presented in Table 9 . The variance reduction is improved by about $6 \%$ compared with the best result obtained without 1854 postseismic effects (Table 8). From this it seems likely that the data set contains a signal from not only 1891 postseismic displacements but also 1854 postseismic displacements. These inversions support our earlier conclusions regarding the lack of slip on segment $B_{2}$ during the 1944 earthquake, 
and the slip accumulation $v=1.8 \mathrm{~cm} /$ year in Suruga Bay. We consider this to be a good working model for crustal deformation in central Honshu since 1854 . We must point out, however, that the observed vertical uplift and horizontal vector data may be satisfactorily explained with a Suruga Trough slip accumulation rate anywhere in the range $v=1-3 \mathrm{~cm} /$ year. Also, the possibility of aseismic slip in the deeper portion of the coupled interplate boundary means that the derived value of $v$ is probably underestimated by several $\mathrm{mm} /$ year. As discussed previously, complete accounting of the deterministic signal in the data should lead to no more than about $60 \%$ variance reduction.

To illustrate the relative importance of tectonic displacements and Nobi postseismic displacements, we show in Fig. 13: (a) the tectonic component of displacement due to slip accumulation and 1944 coseismic offsets, as in Inversion III; this plot is identical to Fig. 2(b), (b) the tectonic component of displacement above augmented by 1854 postseismic displacements, as in Inversion IV, (c) the Nobi postseismic component of displacement, calculated from Inversion IV, and (d) the sum of the tectonic and postseismic components of displacement calculated from Inversion IV. We assume in each of these calculations a slip value of zero for segment $B_{2}$ in the 1944 earthquake, and a slip accumulation rate of $1.8 \mathrm{~cm} /$ year in the Suruga Trough. Note that an arbitrary $20^{\circ}$ clockwise rotation of the displacement fields about the point $\left(36.4^{\circ} \mathrm{N}, 139.0^{\circ} \mathrm{E}\right)$ has been applied to the net displacement field plotted in Fig. 13(d). This rotation was determined visually, and the calculated displacement pattern which includes all postseismic and tectonic effects is seen to be in excellent agreement with the observed displacement pattern (Fig. 2(a)). A comparison of the vectors plotted in Fig. 13(d) with those in Figs. 7 and 9 (which do not include tectonic effects) reveals clear improvement in reproducing the pattern of observed vector displacements; this might be expected because of the $60 \%$ variance reduction achieved by Inversion IV. The $1 \mathrm{~m}$ of relative northwestward displacement of western Suruga Bay relative to the interior of Japan is seen to result primarily from 1891 postseismic displacements (Fig. 13(c)) rather than steady state Philippine Sea convergence (Figs. 11, 13(a)-(b)). It is also noteworthy that the 1854 postseismic displacements tend to subtract from the other components of tectonic strain accumulation and release (Fig. 13(a)), so that the net tectonic displacements (Fig. 13(b)) are generally small compared with the Nobi postseismic displacements.

The vertical postseismic displacements from the 1854 earthquake have a component of uplift of western Suruga Bay relative to eastern Suruga Bay, again in the sense opposite to strain accumulation along the plate boundary (segments A, B, and C). The total subsidence of western Suruga Bay relative to eastern Suruga Bay (defined as the difference in vertical motions between points at $35.1^{\circ} \mathrm{N}, 138.4^{\circ} \mathrm{E}$ and $34.9^{\circ} \mathrm{N}, 139.0^{\circ} \mathrm{E}$ ) between 1889 and 1951 was only about $20 \mathrm{~cm}$, according to the results of Dambara (1968). The strain accumulation model of Table 7 (involving segments A and B but not segment C), combined with the favored model for the 1944 earthquake (involving segments $A$ and $B_{1}$ ), would account for about $8 \mathrm{~cm}$ relative subsidence, leaving $12 \mathrm{~cm}$ due to strain accumulation along the Suruga Trough Fault and other factors. The $12-\mathrm{cm}$ residual can be quantitatively explained in either of two ways: (1) by taking $\nu=0.7 \mathrm{~cm} /$ year and neglecting 1854 postseismic effects, or (2) taking $v$ much higher and including 1854 postseismic effects. The preferred model of Table 9, which includes all 


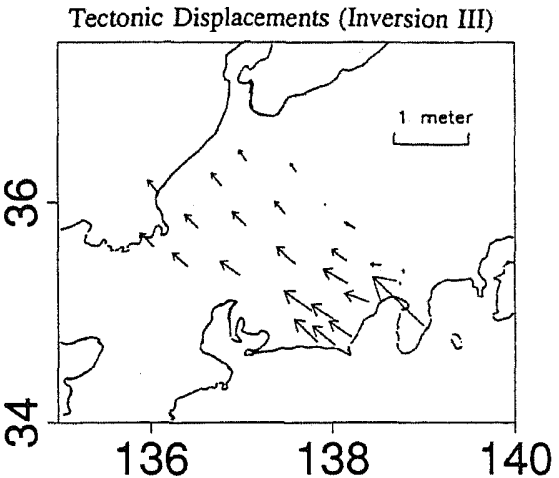

(a)

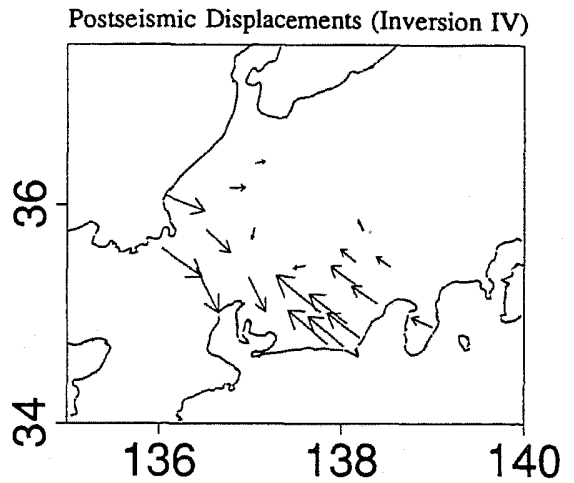

(c)

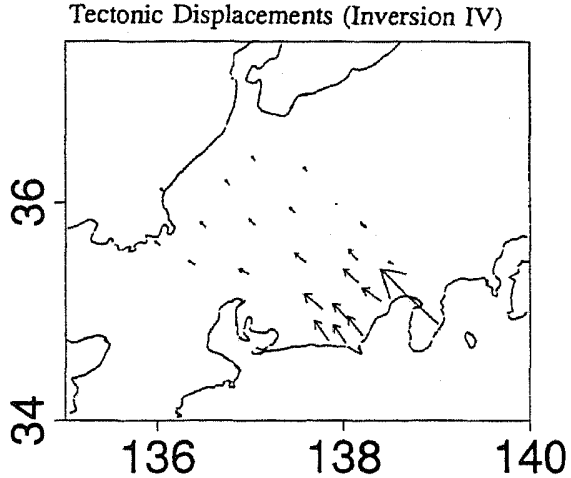

(b)

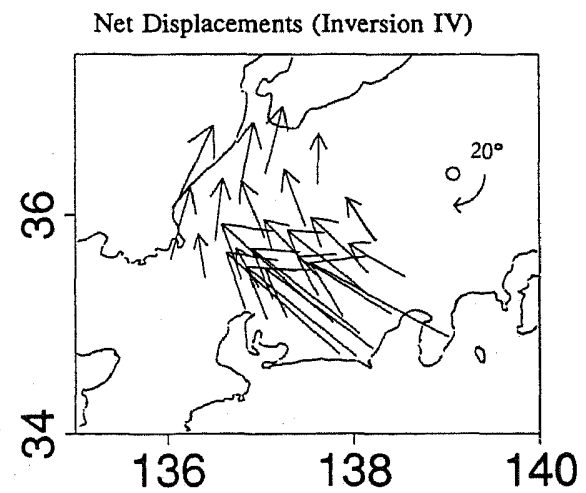

(d)

Fig. 13. (a) Tectonic component of displacement during the period 1896-1951 as calculated in Inversion III. This includes the effects of slip accumulation along the Philippine Sea interplate boundary (Nankai Trough and Suruga Trough) and coseismic offsets during the 1944 Tonankai earthquake. (b) Tectonic component of displacement during the period 1896-1951 as calculated in Inversion IV. This includes the components used in Inversion III plus postseismic displacements following the 1854 Ansei earthquake. (c) Calculated Nobi postseismic displacement vectors for the period 1896-1951 after Inversion IV. (d) Net calculated displacement vectors after Inversion IV, equal to the sum of the displacement fields plotted in (b) and (c). Note that the calculated vectors in (d) have undergone a clockwise rotation of $20^{\circ}$ about the point $\left(36.4^{\circ} \mathrm{N}, 139.0^{\circ} \mathrm{E}\right)$.

components of slip accumulation (with $v=1.8 \mathrm{~cm} /$ year), slip release (1944 earthquake) and 1854 postseismic displacements along the interplate boundary, leads to a net $25 \mathrm{~cm}$ relative subsidence of western Suruga Bay relative to eastern Suruga Bay between 1889 and 1951. So we conclude that because of the effects of 1854 postseismic displacements, the "apparent" slip accumulation rate along the Suruga Trough Fault detected by

Vol. 42, No. 1, 1994 


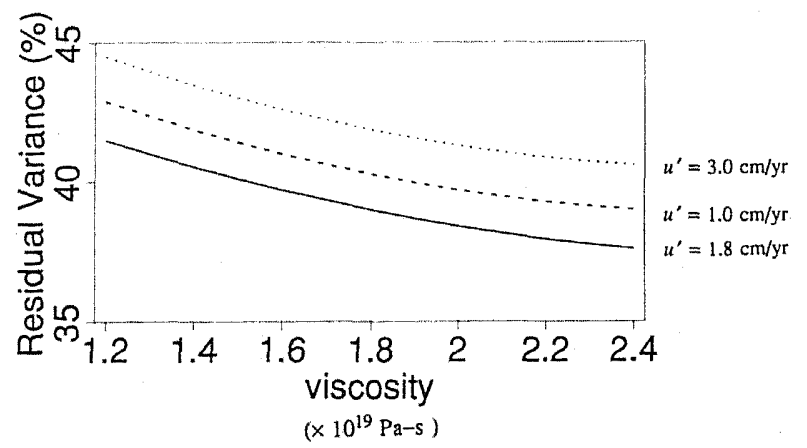

Fig. 14. Residual variance $\chi^{2} / \chi_{0}{ }^{2}$ (where $\chi_{0}{ }^{2}$ is the initial variance) in $\%$ after Inversion IV as a function of viscosity $\eta$ for different values of Suruga Bay slip accumulation rate $u^{\prime}$. The sensitivity of the inversion to viscosity is primarily through the effects of postseismic displacements following the 1854 Ansei earthquake.

vertical displacement measurements between 1889 and 1951 is about $0.7 \mathrm{~cm} /$ year.

Because of the presence of 1854 postseismic displacements in both the horizontal vector data and Dambara's Suruga Bay uplift data, tight bounds may be placed on the sublithospheric viscosity $\eta$. We performed inversions of the horizontal vector data at various values of $\eta$, taking 1854 postseismic effects into account as in Inversion IV. The resulting variance as a function of $\eta$ is shown in Fig. 14 for various values of Suruga Bay slip accumulation. These curves indicate that a Suruga Bay slip accumulation rate of $v=1.8-3 \mathrm{~cm} /$ year leads to a satisfactory fit to the data, and they show that the residual variance does not vary much between $\eta=1.2 \times 10^{19} \mathrm{~Pa} \cdot \mathrm{s}$ and $\eta=2.4 \times 10^{19} \mathrm{~Pa} \cdot \mathrm{s}$. Assuming $v=1.8 \mathrm{~cm} /$ year, the net uplift predicted for western Suruga Bay between 1889 and 1951 varies between -31 and $-16 \mathrm{~cm}$, respectively, for viscosities ranging between these values. The observed $20-\mathrm{cm}$ subsidence discussed above clearly constrains the viscosity to lie near $2 \times 10^{19} \mathrm{~Pa} \cdot \mathrm{s}$. This analysis depends primarily on the validity of our rheological model for Japan, which assumes a spherically stratified rheology with specified elastic plate thickness and asthenospheric relaxation time. The validity of these assumptions is questionable directly at the interplate boundary. Nonetheless, the preceeding discussion is intended to show, at the least, how the apparently small Suruga Bay differential subsidence (only $20 \mathrm{~cm}$ in a 62-year time interval) may be largely a consequence of 1854 postseismic motions.

To sum up these conclusions, analyses of postseismic horizontal displacements lead to the following model for the 1891 Nobi earthquake and 1944 Tonankai earthquake: (1) 7-8 $\mathrm{m}$ of left-lateral slip along the Nukumi-Neodani faults, $7.6 \mathrm{~m}$ of reverse slip along the northeast thrust, and $6.7 \mathrm{~m}$ of reverse slip along the southwest thrust during the Nobi earthquake, (2) $4 \mathrm{~m}$ of slip along fault planes $\mathrm{A}$ and $\mathrm{B}_{1}$ during the Tonankai earthquake, with the earthquake terminating near the Atsumi Peninsula at the junction between fault planes $B_{1}$ and $B_{2}$, (3) asthenospheric viscosity of about $1.6 \times 10^{19} \mathrm{~Pa} \cdot \mathrm{s}$ beneath central Honshu, and (4) a slip accumulation rate in Suruga Bay of about 
$2 \mathrm{~cm} /$ year, about $1-2 \mathrm{~cm} /$ year less than the net tectonic convergence rate across the Nankai Trough. We shall now discuss how the 1891 fault model must be revised when proper account is taken of additional information, particularly topography and leveling. Nevertheless, the model we have derived in this section on the basis of postseismic displacements is remarkably close to the revised model.

\section{Nature of the Blind Thrust Faults}

The thrust faults composed of segments Nos. 4 and 5 extend $100 \mathrm{~km}$ northeastward from Nagoya. The reverse faulting associated with it does not appear to reach the surface, but there is a clear topographic bulge directly above the northeast segment. These are diagnostic features of a blind thrust fault (Stein, 1990). The topography east of the Nobi Plain rises from Ise Bay northeast along the Median Tectonic Line, achieving about $2,900 \mathrm{~m}$ altitude in the Kiso Range bordering the northeast thrust. The lack of a topographic expression above the southwest thrust suggests that this segment had a deeper $(>15 \mathrm{~km})$ slip component during the Nobi earthquake, and this also suggests that this segment has been less active than the northeast segment over geologic time. Figure 14 of Ishida (1984) presents depth sections of recent seismicity along sections crossing the Tokai Province (her profiles 3 and 4). The northwest boundary of seismicity in her profile 4 could imaginably define the base of a northwest-dipping thrust fault which coincides with the northeast thrust. This feature also shows up in the depth section of a more recent study (Ishida, 1992) along her profile T2 in the range -90 to $-50 \mathrm{~km}$. There is, in contrast, no suggestive shallow seismic activity near the southwest thrust, again suggesting that this segment has different characteristics than we have yet inferred.

The topography representative of the northeast segment and projected along strike is shown by the solid line in Fig. 15(a). To model this observed topography, we have constructed a model for long-term slip associated with the fault. It accounts for accumulated coseismic offsets along a fault buried to a depth $d$ and extending to the base of the elastic plate with $45^{\circ}$ dip. These coseismic offsets are allowed to completely relax to simulate long-term slip on a $33-\mathrm{km}$-thick elastic plate. This formulation for the modelling of long-term slip is similar to that developed by King et al. (1988), except that we allow for the possibility of faulting which does not penetrate the entire elastic lithosphere. In addition, we employ a much thicker elastic plate than is used in their calculations, and for simplicity we ignore the effects of sedimentation and erosion; these effects are likely minor because of the relatively young age of the generated topography and because only slight lithospheric flexure would result from any additional loads on the relatively thick elastic plate. Figure 15 (b) shows the coseismic and coseismic + relaxed vertical ground displacement resulting from $10 \mathrm{~m}$ of long-term slip for three different values of $d$. The coseismic + relaxed calculations evaluate the ground displacement after the sublithosphere is allowed to completely relax. Note that the mean width of the topographic bulge is considerably broader after relaxation, and that this width is a moderately sensitive function of $d$. In the case $d=0.1 \mathrm{~km}$, when the fault penetrates nearly the entire elastic lithosphere, the relaxed (postseismic) displacements indicate a net subsidence of about $-0.15 \times S_{0}$ directly above the fault, where $S_{0}$ is the fault slip 


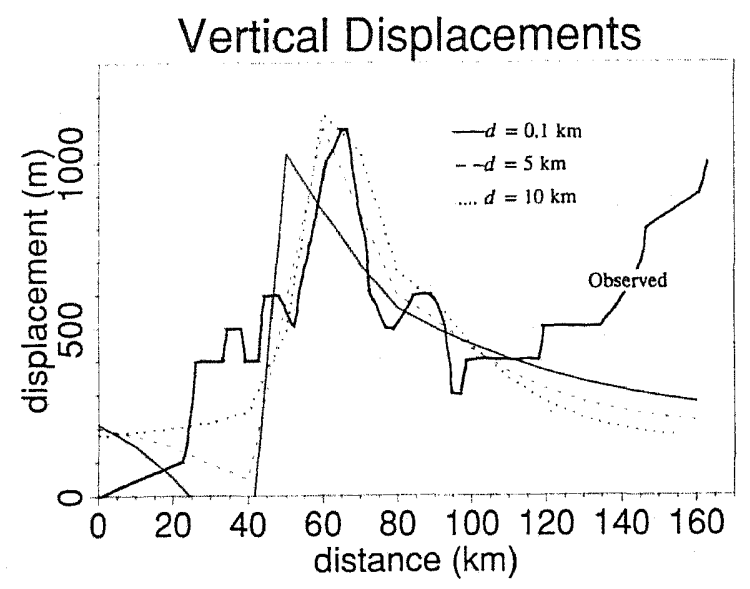

Fig. 15(a)

Fig. 15. (a) Comparison of observed and calculated topography. The observed topographic profile above the northeast thrust, shown by the solid line, is resolved along a vertical plane striking southeast-northwest and averaged along the length of the northeast thrust (Fig. 8). $x=0 \mathrm{~km}$ corresponds to the Pacific shoreline, and increasing distance is towards the northwest. The calculations assume a total slip of $2 \mathrm{~km}$, and a reference depth of $200 \mathrm{~m}$. The surface projection of the bottom of the thrust fault $(x=0 \mathrm{~km}$ in $\mathrm{b}-\mathrm{c})$ corresponds to $x=80 \mathrm{~km}$ in this plot. Comparison of the calculated curves with the observed topography suggests that the northeast thrust fault is buried $5-10 \mathrm{~km}$ beneath the surface. (b) Vertical uplift due to displacement along the buried thrust fault. Calculations are done for dip $=45^{\circ}$, slip $=10 \mathrm{~m}$, bottom depth of faulting $=33 \mathrm{~km}$, and depth of burial $d=0.1,5$, or $10 \mathrm{~km}$. Dotted lines: Coseismic component. Solid lines: Coseismic+Relaxed. The Coseismic+Relaxed calculations are equivalent to coseismic offsets in an elastic plate (of thickness $33 \mathrm{~km}$ ) overlying a viscoelastic medium which is allowed to completely relax.

( $=10 \mathrm{~m}$ ). This is in contrast with figure 7 of Cohen (1984), which predicts a net uplift of about $+0.05 \times S_{0}$ above the fault. We find that the difference in results arises from the finite fault length used in our calculations. The ratio of fault length to elastic plate thickness used here is about 3, while the calculations of Cohen (1984) are twodimensional and use an infinite fault length. It is also found, regardless of fault length, that the vertical postseismic motions are positive for a thrust fault which is sufficiently buried (for example, Fig. 15(b) with $d=10 \mathrm{~km}$ ).

Comparing Fig. 15(a) and (b), the observed topography between $x=40$ and $100 \mathrm{~km}$ is roughly symmetric about its maximum at $x=65 \mathrm{~km}$. It is poorly fit by the curve $d=0.1 \mathrm{~km}$, and its shape is better matched by the curves $d=5 \mathrm{~km}$ or $d=10 \mathrm{~km}$. This is shown convincingly in Fig. 15(a), where the observed and calculated topography are compared. In these calculations, we have taken the total slip to be $2 \mathrm{~km}$ and taken the reference depth to be $200 \mathrm{~m}$. The surface projection of the bottom of the proposed thrust fault (see Fig. 8) is located at $x=95 \mathrm{~km}$, but we have relocated it to $x=80 \mathrm{~km}$ 

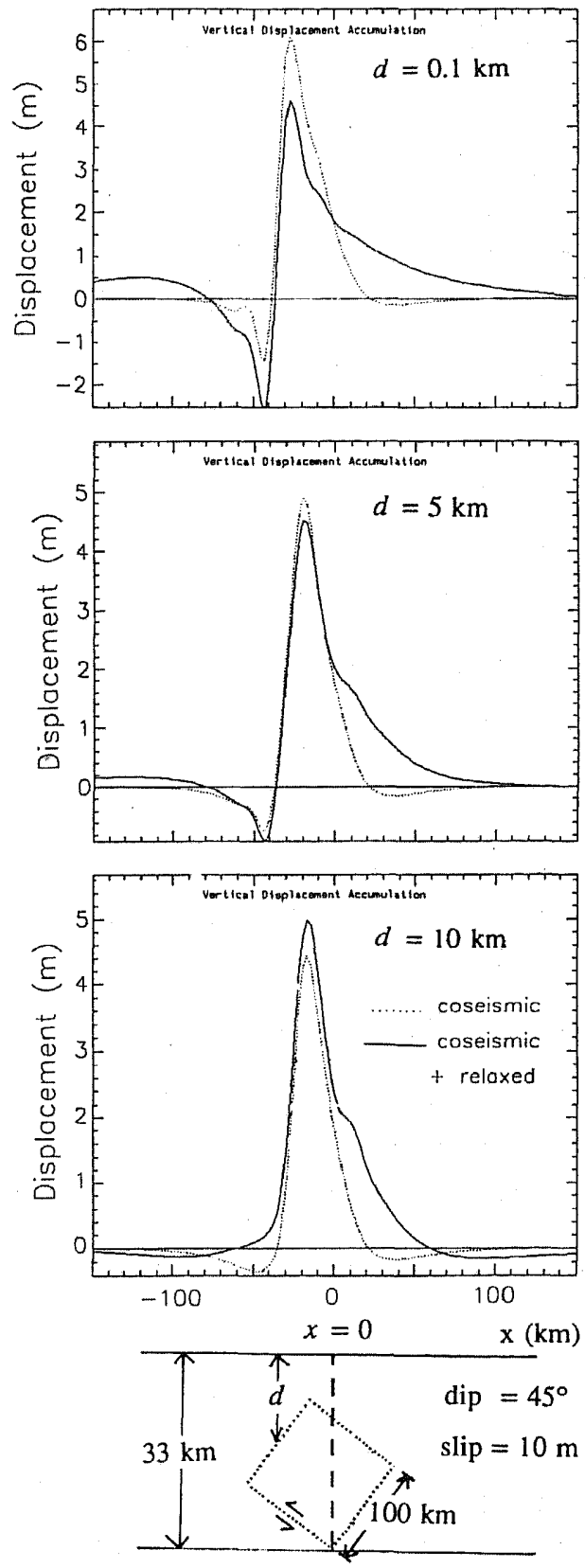

Fig. 15(b)

Vol. 42, No. 1, 1994 
to construct the calculated topography in Fig. 15(a). The comparison of observed and calculated topography shows that the northeast thrust fault must be buried some 5-10 km below the surface. The broad $(60 \mathrm{~km})$ width of the topography indicates that coseismic offsets are not sufficient to explain the pattern, supporting the existence of a viscoelastic sublithosphere below a depth of $20-30 \mathrm{~km}$. The misfit in the topography profile beyond $x=120 \mathrm{~km}$ in Fig. 15(a) is due to volcanic mountain building processes near Mt. Ontake, and is unrelated to the faulting process described here.

The postseismic uplift pattern east of Nagoya (Dambara, 1968; Hayashi, 1969) also suggests that the northeastern thrust fault is buried by several $\mathrm{km}$. This is because the postseismic vertical motions from a thrust fault which ruptures the entire elastic lithosphere lead to a net depression above the fault, rather than a net uplift, as discussed above. Another constraint is the Bouger gravity anomaly pattern, shown in figure 5 of Kanaori et al. (1992). The long wavelength component of the inland Bouger anomaly pattern, characterized by a broad negative gradient in the northwest direction, is due to the subduction of the Philippine Sea plate. The free-air gravity anomaly due to steady state plate convergence for southwest Honshu (Sato and Matsu'ura, 1992, 1993) includes the subducted slab component plus those effects due to the generated long wavelength topography. The Bouger anomaly pattern contains shorter wavelength signal and displays higher gravity anomalies in the southeast quadrants $(+30-40 \mathrm{mGal})$ than in the northwest quadrants $(-10-0 \mathrm{mGal})$. This is here tentatively interpreted as reflecting the relative elevation of intracrustal density discontinuities (Conrad discontinuity) directly below the northeast thrust, due to long-term reverse motion along this fault. This interpretation would be strengthened by shifting our preliminary location of the northeast thrust about $15 \mathrm{~km}$ towards the southeast, so that both the topography and gravity patterns suggest that the northeast thrust fault is located slightly more towards the southeast than is indicated in Fig. 8. In any case, the steep decrease in gravity anomaly in the northwest direction supports our choice of a northwest dip for the northeast thrust.

If the thrust faults accommodate perhaps $1 \mathrm{~cm} /$ year of the total Philippine Sea plate convergence, then this suggests that they are relatively young, roughly 200,000 years old. This partitioning of the $4 \mathrm{~cm} /$ year total tectonic convergence into the inland thrust faults requires the existence of an additional structure(s) to connect the southwest and northeast boundaries of the thrust faults with the Nankai Trough. Kanaori et al. (1990, 1992) identified several young left-lateral strike-slip faults in central Honshu, activated in late Quaternary time. Their Fault III-3 may define the northeast boundary of the northeast thrust. Their Fault II-3 and Fault II-4 and its extension may act as an accommodation structure between the Nankai Trough and the southwest thrust. Interestingly, two large earthquakes occurred along this roughly defined left-lateral fault zone in 1894, shortly after the Nobi earthquake (Kanaori et al., 1992; their Fig. 4). This accommodation structure may have even ruptured during the Nobi earthquake. Mikumo and Ando (1976) deduced a southward extension of the Nukumi-Neodani faults with a deep slip component which might connect laterally with the southwestern boundary of the southwest thrust. We have checked whether any southern extension of the Nukumi-Neodani faults could explain the geodetic postseismic data, and found that a model utilizing only the Nukumi-Neodani faults and any conceivable southern 
extension provides a poor fit to the data.

The long-term compressional deformation suggested by the inland thrust faults appears to be part of a partitioning of strain both inland and oceanward of the eastern Nankai Trough and Suruga Trough. The oceanward component of this strain partitioning is represented by the Zenisu Ridge and "South of Zenisu" Ridge, both intraoceanic thrust zones (Lallemant et al., 1989). The oceanward and inland strain distribution may tentatively be interpreted as one unit, representing the response of the Philippine Sea oceanic plate and its inland projection to the collision of the Izu-Ogasawara Ridge with central Japan (Huchon and Kitazato, 1984; Huchon and Angelier, 1987). The Nukumi-Neodani faults, segment $X$ and its southeastward continuation (as delineated by large earthquakes in 1894 and 1945) represent a sharp dividing line between two structural provinces-distributed onland and oceanward compressional deformation to the east, and concentrated accommodation of interplate convergence along the Nankai Trough to the west (X. LePichon, F. Pollitz, and J.-P. Cadet, manuscript in preparation).

\section{Implications of Leveling Data}

Careful fault models of the 1891 earthquake which explain the observed surface displacements and most of the leveling data have been put forth by Mikumo and Ando (1976). Each of their alternative fault models explains the distribution of lateral slip, localized fault uplift and coseismic leveling observations, with the notable exception of one leveling line which continues south from the Neodani Fault (segment 2) and parallels its suspected southeastern continuation. This leveling line is shown in Fig. 14 together with the two leveling lines previously analyzed by Mikumo and Ando (1976). We employ the leveling curves presented by Muto and Kawabata (1933). The times of pre- and post-Nobi earthquake measurements are:

B.M. 190-B.M. 185, 1885-1896.

B.M. 185-B.M. 740, 1890-1894/1895.

B.M. 185-B.M. 693, 1889-1894.

B.M. 185-B.M. 166, 1885-1894/1895.

To fit these leveling lines, we derived a fault model which combines features of the fault model presented by Mikumo and Ando (1976; their figure 2) and that presented here (Table 9). This fault model is presented in Fig. 16. We have adopted a modified Mikumo and Ando model for segments 1 and 2, which have dominantly left-lateral slip with a component of dip-slip motion (southwest side up). We have included a revised southeast extension of the Nukumi-Neodani faults as postulated by Mikumo and Ando (segment $X$ ) and a revised position of the southwest buried thrust fault (segment $Y$ ). The reasons for these revisions are as follows:

1. The dip-slip component of segment 1 is modified to be $1.0 \mathrm{~m}$ (instead of Mikumo and Ando's $2.0 \mathrm{~m}$ ) because this leads to a better fit of the leveling profiles.

2. We have specified $7 \mathrm{~m}$ pure left lateral slip along segment 2, as was obtained in Table 9. Since the southern portion of Mikumo and Ando's Neodani Fault also has $7 \mathrm{~m}$ slip, the contribution of segment 1 to the leveling profiles is essentially the same in either case.

3. The leveling lines B.M. 190-B.M. 740 and B.M. 185-B.M. 693 demand a

Vol. 42, No. 1, 1994 


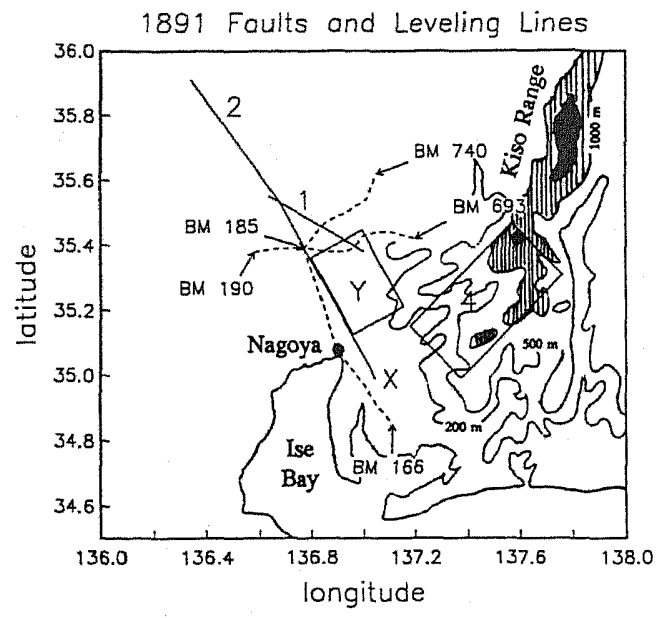

Fig. 16. Fault geometry of 1891 Nobi earthquake synthesized from modelling of postseismic relaxation, leveling, and topography. Fault segments 1,2, and $X$ are left lateral strike slip faults, and segments $Y$ and 4 are thrust faults. Fault geometry and slip parameters are explained in the text. Leveling lines containing a coseismic signal from the Nobi earthquake are indicated. The topography around segment 4 is superimposed; solid shaded regions are areas of altitude greater than $2,000 \mathrm{~m}$.

dip-slip component of segment $X$ raising its northeast side up about $1 \mathrm{~m}$.

4. The leveling line B.M. 185-B.M. 166 shows B.M. 185 subsiding about $12 \mathrm{~cm}$ relative to stable regions to the southeast. This can not happen if segment $X$ passes to the west of B.M. 185. Therefore segment $X$ must pass just to the east of B.M. 185 .

5. We postulate that segment $X$ concides with Fault II-3 and its extension as delineated by Kanaori et al. (1992). The site of the 1894 earthquake is taken as the southeast termination of segment $X$. This is justified by the patterns of pre- and post-Nobi earthquake activity, in which the southeast extension is clearly delineated. Note that our model actually can not distinguish between the effects of the 1891 and 1894 earthquakes as far as segment $X$ and the leveling data are concerned.

6. The southwest thrust (segment 5 of Fig. 8) is revised to a more northerly position with deeper $(>15 \mathrm{~km})$ slip components and its southwest boundary taken to be segment $X$. This segment is renamed segment $Y$ in Fig. 14. In its original position, segment 5 is located too far south, leading to a predicted coseismic uplift front which is not observed south of Nagoya.

Note that the positions of segments 1,2 , and $X$ differ slightly from those given by Mikumo and Ando. Every strike-slip fault segment is assumed to be a vertical fault with uniform slip in the depth range $0.1-33 \mathrm{~km}$. We have assigned the fault parameters of Table 9 (top row) to segment 4 : $\operatorname{dip}=45^{\circ}$, strike $=225^{\circ}$, rake $=90^{\circ}$ (pure dip-slip) and slip $=7.6 \mathrm{~m}$. In accordance with our modelling of the topography, the lower/upper fault depths of segment 4 are assigned $33 \mathrm{~km} / 8 \mathrm{~km}$. By a process of trial and error, we have derived the following fault geometry for segment $Y$ : dip $=31^{\circ}$, strike $=241^{\circ}$, 
rake $=90^{\circ}$ and lower $/$ upper fault depths $=33 \mathrm{~km} / 15 \mathrm{~km}$. Two possible slip models for segment $Y$ will be considered here:

A. Uniform slip $=4.25 \mathrm{~m}$ throughout the depth range $15-33 \mathrm{~km}$.

B. Trapezoidal slip distribution, with slip at a depth of $33 \mathrm{~km}=6.2 \mathrm{~m}$ and slip at a depth of $15 \mathrm{~km}=2.3 \mathrm{~m}$.

Considering only coseismic offsets, the fit of this fault model to the leveling data is shown by the solid lines in Fig. 17(a)-(c). The corresponding fits without the thrust segments are shown by the dashed lines. Along the line B.M. 185-B.M. 166 in Fig. 17(a) we have included the calculated curves according to case $A$ above and for the fault model with neither the thrust faults nor segment $X$.

The calculated curves (case B) overpredict the step across segment 1 along the profile B.M. 715-B.M. 693 (Fig. 17(b)) and underpredict the step across segment 1 along the profile B.M. 190-B.M. 740 (Fig. 17(c)), suggesting that segment 1 dip-slip motion decreases towards its southeastern terminus. A greater dip-slip component along the northern part of segment 1 would also better fit the observed rise in offset between segment 1 and B.M. 740. The gradual rather than a sharp increase in vertical offset along the line B.M. 190-B.M. 740 east from B.M. 190 indicates that either segment $X$ is buried by a few km in the region B.M. 190-B.M. 185 or it has multiple fault splays there. Although the lines B.M. 190-B.M. 740 and B.M. 185-B.M. 693 are not greatly affected by the thrust components, the line B.M. 185-B.M. 166 (Fig. 17(a)) is greatly improved by inclusion of thrust components. Without the thrust components, most of this line is consistently misfit by about $30 \mathrm{~cm}$. This conclusion is not very sensitive to realistic changes in either the strike of segment $X$ or the position of its southern termination. Both segment $X$ and the thrust faults are clearly needed in order to fit this profile. The misfit in the case with the thrust faults reaches up to $9 \mathrm{~cm}$, but qualitatively the calculated curve reproduces well the local increase in vertical offset south of B.M. 185. The remaining misfit could arise from variable slip along segment $X$. To be kinematically consistent with the slip of segment $Y$, segment $X$ must have a smaller dip-slip component and higher left lateral strike-slip component south of the southern termination of segment $Y$. Thus, the negative values of the calculated leveling curve south of Nagoya are probably due to overestimating the dip-slip component along the southern part of segment $X$. A higher left-lateral strike-slip component for the southern part of segment $X$ is supported by the occurrence of the 1894 earthquake in that region and the higher concentration of aftershock activity in that region during the 10 years following the Nobi earthquake (JMA, unpublished). The contribution of segment 4 to the profile B.M. 185-B.M. 166 is only on the order of $5 \mathrm{~cm}$.

To summarize these results, the leveling data puts tight constraints on the location and fault geometry of the southwest thrust, requiring that it be located near the wedge between segments 1 and $X$. The southwest thrust has significant slip only below $15 \mathrm{~km}$, while the zone of significant slip along the northwest thrust initiates at somewhat more shallow depths $(5-10 \mathrm{~km})$. The northeast thrust structure appears to be the subterranean continuation of the exposed thrust fault which bounds the Kiso Range along its eastern flank. The depositional history of the Kiso River (Kaizuka et al., 1964) indicates that the uplift of the Kiso Range has occurred dominantly in Quaternary time. 


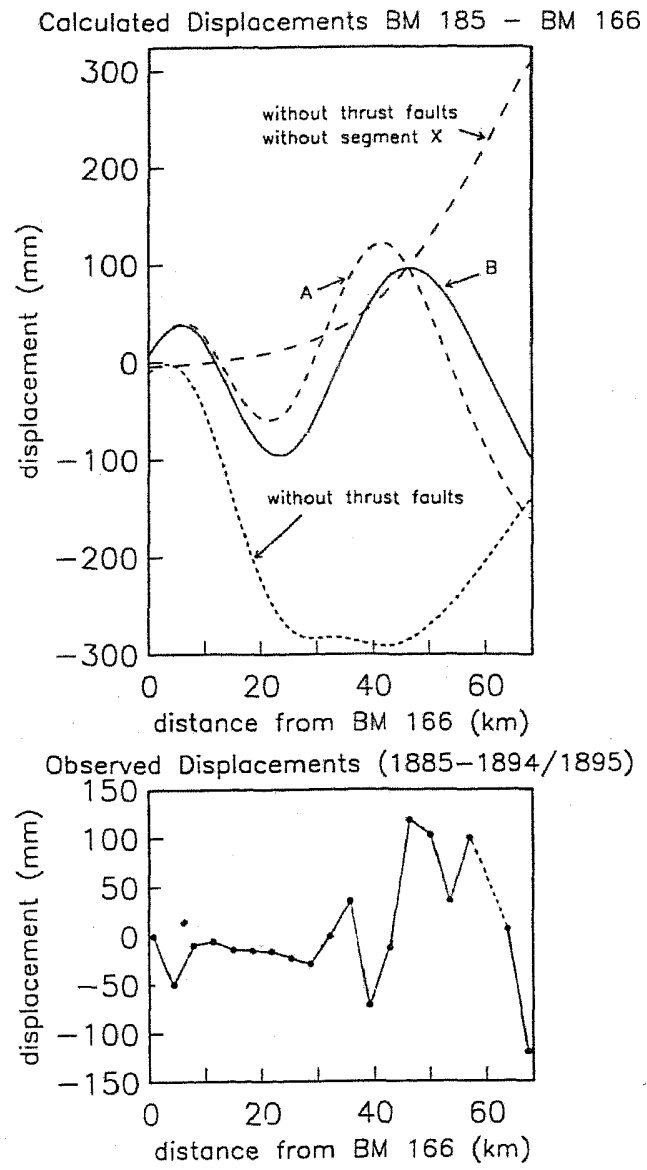

Fig. 17(a)

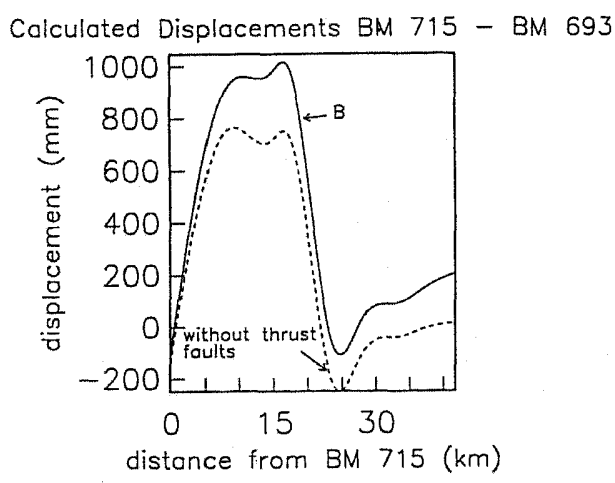

Observed Displacements (1889 - 1894)

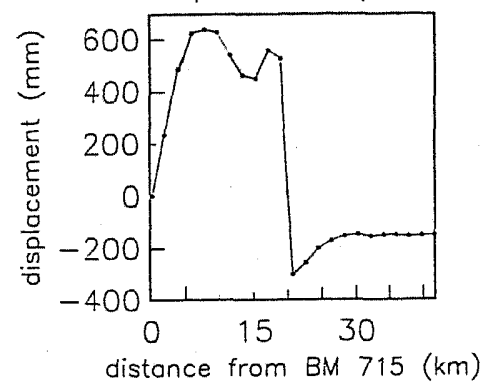

Fig. 17(b)

Fig. 17. Observed and calculated vertical offset corresponding to Nobi coseismic displacements along several leveling profiles: (a) B.M. 185-B.M. 166, (b) B.M. 715-B.M. 693, (c) B.M. 190-B.M. 740. In (a), case A refers to uniform slip along thrust segment $Y$ and case B refers to trapezoidal slip along segment $Y$ (see text).

\section{Preferred Model}

On the basis of synthesized leveling, topography, and postseismic displacement modelling, we summarize below our "Preferred Model" for the various components of strain accumulation and release affecting the Tokai District since 1854.

Preferred Model

1944 Slip: Fig. 10 (left) and Table 6, $B_{2}=0 \mathrm{~m}$

Philippine Sea Convergence Rate: Fig. 10 (right) and Table 7, C=1.8 cm/year 1891 Earthquake: Fig. 16 and Table 10

Sublithospheric Viscosity: $\eta=1.6 \times 10^{19} \mathrm{~Pa} \cdot \mathrm{s}$ 

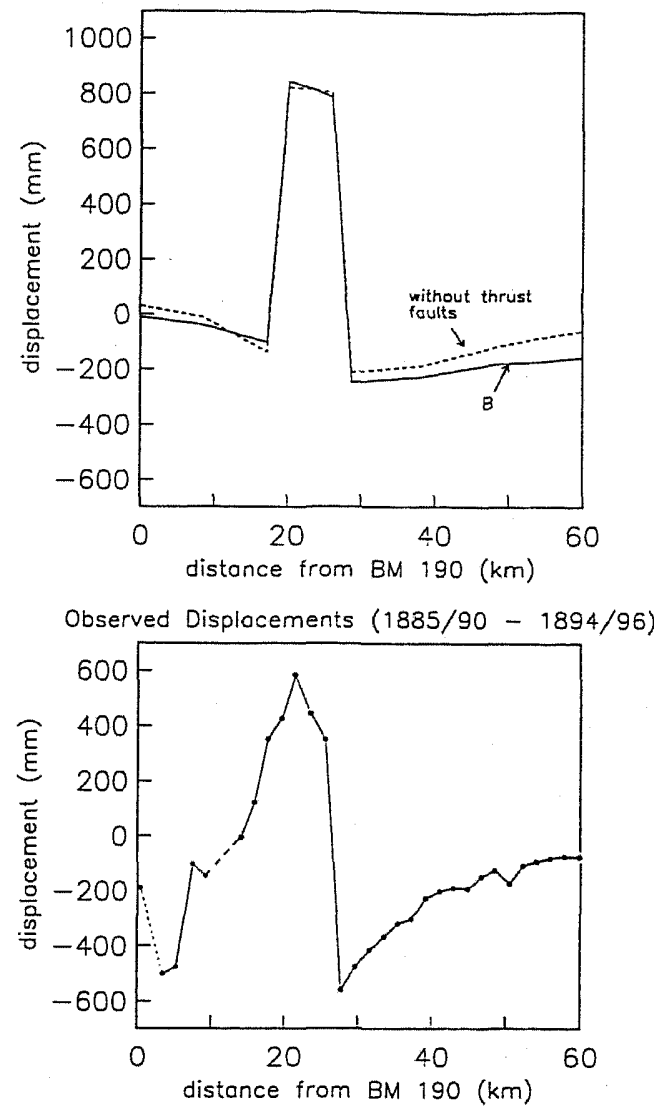

Fig. 17(c)

We wish to point out that the revised fault model (Fig. 16) has remarkably the same geographic pattern as the pre- and post-Nobi earthquake activity. This is shown in Fig. 18, where the pre- and post-Nobi seismicity (Davison, 1921) have been superimposed on the 1891 faults determined in this section. It is also worth considering a triggering model for the complicated series of fault components. Mikumo and Ando (1976) have shown that the Nobi earthquake initiated rupture at the northwest tip of segment 2 and the rupture propagated southeastward. At the junction of segments 2 , 1 , and $X$, the rupture continued propagating along segments 1 and $X$. Segments 1 and $X$ accommodated about 1.5 and $1 \mathrm{~m}$, respectively, of left-lateral slip and $1 \mathrm{~m}$ each of dip-slip motion such that the triangular wedge between segments $1, X$, and $Y$ was uplifted about $1 \mathrm{~m}$. The uplift and relative southeastward displacement of this triangular wedge triggered the rupture of the northwest-dipping thrust segment $Y$. This could be responsible for the severe damage reported above this wedge, which was caused in part by strong vertical ground motion (Muramatu, 1963). The triggering mechanism of 
Table 10. Synthesized 1891 fault model.

\begin{tabular}{ccccccccccc}
\hline Segment & Type & Strike* & $\begin{array}{c}\text { Dip } \\
\left({ }^{\circ}\right)\end{array}$ & $\begin{array}{c}\text { Rake } \\
\left({ }^{\circ}\right)^{* *}\end{array}$ & $\begin{array}{c}\text { Length } \\
(\mathrm{km})\end{array}$ & \multicolumn{2}{c}{ Endpoint*** } & Lat $\left({ }^{\circ} \mathrm{N}\right)$ & Lon $\left({ }^{\circ} \mathrm{E}\right)$ & Bottom/top \\
depth $(\mathrm{km})$ & $\begin{array}{l}\text { Slip } \\
(\mathrm{m})\end{array}$ \\
\hline 1 & Strike-slip & 120 & 90 & 34 & 38 & 35.38 & 137.00 & $33 / 0.1$ & 1.80 \\
2 & Strike-slip & 144 & 90 & 0 & 51 & 35.54 & 136.67 & $33 / 0.1$ & 7.62 \\
$X$ & Strike-slip & 332 & 90 & 45 & 70 & 35.54 & 136.70 & $33 / 0.1$ & 1.40 \\
4 & Thrust & 225 & 45 & 90 & 50 & 35.23 & 137.08 & $33 / 8$ & 7.60 \\
$Y$ & Thrust & 241 & 31 & 90 & 20 & 35.36 & 136.80 & $33 / 15$ & 4.20 \\
\hline
\end{tabular}

* Degrees clockwise from North, with the fault dipping down to the right of the strike direction. ${ }^{* *} 0^{\circ}$ is pure left lateral slip, $90^{\circ}$ is pure reverse slip. ${ }^{* * *}$ Lowermost corner of fault closest to strike direction.
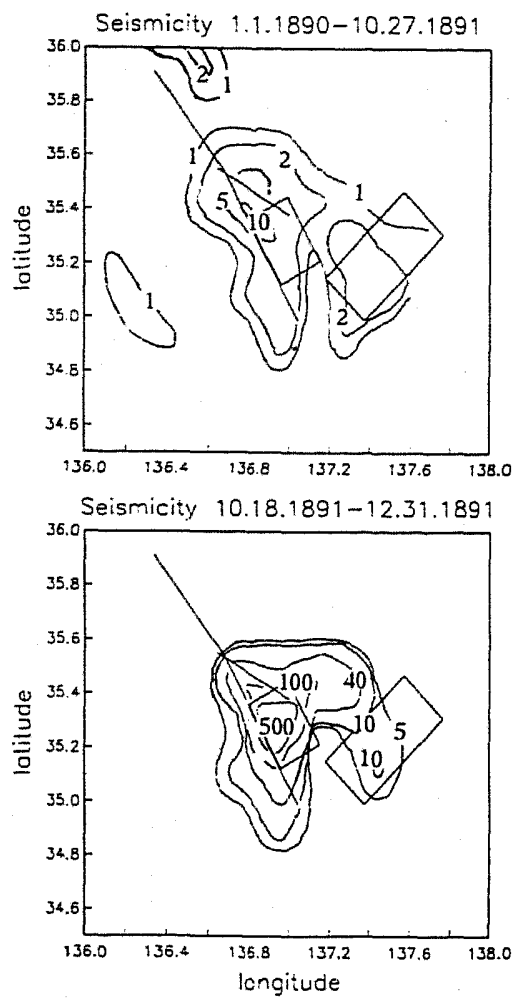

Fig. 18. Pre- and post-Nobi seismicity (Davison, 1921) superimposed on the 1891 faults.

segment 4 is unclear. It is conceivable that segment 4 extends southwestward as far as segment $X$ but with diminished slip. In this case the rupture of segment $X$ could trigger the rupture of segment 4 . Alternatively, the pre- and post-Nobi earthquake seismicity patterns suggest that slip on segment 4 was triggered by segment 1 , which may have 
ruptured farther to the southeast without breaking the surface. Such a scenario can not be ruled out by the leveling data.

It must be emphasized that, given the long wavelength nature of postseismic displacements, the revised fault model of Fig. 16 is nearly equivalent to the original fault model of Fig. 8. As long as the seismic moment of the revised fault model is comparable with that of the original model, the predicted postseismic displacement fields are practically the same. We have verified this by calculating the variance reduction from the Preferred Model in Inversion IV, allowing segment 4 to have variable values in forward calculations. The results are shown in Fig. 12. The obtained variance reduction increases monotonically as a function of segment 4 slip in the slip range considered (the maximum is at $10.2 \mathrm{~m}$ ). The lack of strong felt intensities directly above segment 4 suggests that it accommodated somewhat less than $7 \mathrm{~m}$ of slip or that it slipped aseismically in a slow rupture. The felt seismicity pattern (Fig. 18) and the postseismic uplift pattern (Dambara, 1968; Hayashi, 1969) are the strongest independent evidence that some form of moment release occurred along segment 4 . In the absence of hard independent constraints for the slip of segment 4, its allowable slip must be limited by the variance reduction which is consistent with the noise level in the data. This maximum variance reduction was previously estimated to be about $60 \%$. If neglected deterministic signal amounts to $5 \%$ of the initial variance, then segment 4 slip should not exceed $7.6 \mathrm{~m}$, if our assumed viscosity value is correct. The slip value of segment 4 could be effectively reduced by about $25 \%$ if the asthenospheric viscosity were halved. If segment 4 flattens at depth, as is commonly observed for other thrust fault zones (e.g., Wentworth et al., 1984), then its slip could once again be effectively reduced. A possible candidate for unmodelled signal is the unknown strike-slip motion accommodated by segment $X$ and its southern extension. The occurrence of the large 1894 and 1945 Mikawa earthquakes along this line, as well as concentrated sand liquifaction observed throughout the area of the Nobi Plain during the 1891 earthquake (Muramatu, 1963) suggests more than $1 \mathrm{~m}$ of left lateral slip along segment $X$ and possibly farther south during the period 1891-1894. The associated coseismic signals from these earthquakes are negligible within the chosen network, but their postseismic signals could account for a fraction of the initial variance. Given the limited information available for the Nobi earthquake, it is obviously difficult to discriminate among the various possibilities.

\section{Conclusions}

The principal conclusions of this study are as follows:

1. The horizontal displacement field in central Honshu between 1896 and 1951 is poorly explained by a model of only tectonic strain accumulation and release, but well explained by these tectonic motions plus postseismic displacements following the 1891 Nobi earthquake. The signal in the observed horizontal deformation field is found to be dominated by Nobi postseismic displacements.

2. A corollary of this result is that the central Honshu crust and upper mantle behave like an elastic lithosphere overlying a viscoelastic sublithosphere of unresolvably large thickness. This suggests that the relatively young Philippine Sea subducting slab 
rides passively with the sublithospheric flow generated by stress release in the elastic lithosphere.

3. A model which includes only Nobi postseismic displacements due to the strike-slip components of the event yields a poor fit to the deformation data. The modelling strongly suggests the participation of two newly identified blind thrust faults in the Nobi earthquake. The combined thrust structures are about $70 \mathrm{~km}$ long and strike northeast-southwest. The top of the western and eastern thrust faults are buried by $15 \mathrm{~km}$ and $5-10 \mathrm{~km}$ with fault lengths of 20 and $50 \mathrm{~km}$, respectively. Pre-Nobi earthquake activity, aftershock activity, the postseismic uplift pattern, and the topography and gravity patterns all support the existence of these blind thrust faults. Leveling data provides constraints on only the western thrust fault and contains a clear coseismic signal from it. Modelling of the leveling data also implies several meters of reverse slip along the western thrust fault during the Nobi earthquake. Given the tradeoffs of the modelling with respect to viscosity and fault geometry, particularly for the northeast thrust, the Preferred Model described in the previous section should be interpreted as representing the overall compressive horizontal moment release rather than absolute estimates of the slip.

4. The modelling suggests that the 1944 Tonankai rupture stopped well before the Suruga Trough, at about the Atsumi Peninsula. In addition, the predicted displacement fields show a strong sensitivity to the long-term slip accumulation rate along the Suruga Trough. The best value is found to be $1.8 \mathrm{~cm} / \mathrm{year}$, which is consistent with the long-term uplift rate of western Suruga Bay relative to eastern Suruga Bay; however, this value may be underestimated by several $\mathrm{mm} / \mathrm{year}$.

5. The modelling is moderately sensitive to postseismic displacements following the 1854 Ansei earthquake. The vertical component of these postseismic displacements in the Suruga Trough during the period 1889-1951 may be compared with the observed uplift around Suruga Bay during this same period. This enables us to constrain the central Honshu sublithospheric viscosity to be close to $2 \times 10^{19} \mathrm{~Pa} \cdot \mathrm{s}$.

We wish to test several hypotheses in future studies; in particular, to refine the estimates of the minimum faulting depth and total offset with quantitative modelling of the Bouger gravity anomaly pattern and the postseismic uplift pattern. We would also like to gain more insight into just how much of the Philippine Sea interplate convergence is partitioned into intraplate strain accumulation. This would enable us to estimate the recurrence time for the Nobi earthquake and to refine our estimate of the age of the buried thrust structures.

This work was performed at the Carnegie Institution of Washington, Institut de Physique du Globe, Paris and Geophysikalisches Institut, Universitaet Karlsruhe. Pollitz has been partially supported by a postdoctoral fellowship from the Carnegie Institution of Washington, the Geoscope Program of IPGP and the Alexander von Humboldt Foundation. We are grateful to Professor Aoki of Nagoya University and the staff at the Observation Center for Earthquake Prediction, Tohuko University, for valuable consultations during the course of this research. I. Muramatu has been very helpful with discussions and providing useful reference material. We are grateful to a number of other colleagues for stimulating discussions, especially I. L. Cifuentes (who also assisted with the topography figure), A. Linde, T. Takanami, and S. Kaneshima of the Carnegie 
Institution of Washington; P. Briole, C. Ruegg, and O. Scotti of Institut de Physique du Globe; $\mathrm{X}$. LePichon of Ecole Normale Superieure, and J.-P. Cadet of Department de Geotectonique, Universite P. et M. Curie.

\section{REFERENCES}

Ando, M., Seismo-tectonics of the 1923 Kanto earthquake, J. Phys. Earth, 22, 263-277, 1974.

Chamot-Rooke, N. and X. LePichon, Zenisu Ridge: mechanical model of formation, Tectonophysics, 160, 175-193, 1989.

Cohen, S. C., Postseismic rebound due to creep of the lower lithosphere and asthenosphere, Geophys. Res. Lett., 8, 493-496, 1981.

Cohen, S. C., A multilayer model of time dependent deformation following an earthquake on a strike-slip fault, J. Geophys. Res., 87, 5409-5421, 1982.

Cohen, S. C., Postseismic deformation due to subcrustal viscoelastic relaxation following dip-slip earthquakes, J. Geophys. Res., 89, 4538-4544, 1984.

Dambara, T., Vertical movements of Japan during the past 60 years; IV Chubu district, J. Geod. Soc. Jpn., 13, 66-74, 1968.

Davison, C., A Manual of Seismology, Cambridge University Press, New York, 249 pp., 1921.

Harada, T., Precise readjustment of old and new first order triangulation and the result in relation with destructive earthquakes in Japan, Bull. Geogr. Surv. Inst., 12, 5-64, 1967.

Harada, T. and N. Isawa, Horizontal deformation of the crust in Japan: result obtained by multiple fixed stations, J. Geod. Soc. Jpn., 14, 101-105, 1969.

Hashimoto, M., Finite element modelling of deformations of the lithosphere at an arc-arc junction: the Hokkaido corner, Japan, J. Phys. Earth, 32, 373-398, 1984.

Hayashi, T., A study of the vertical movements of the earth's crust by means of precise leveling, Bull. Geogr. Surv. Inst., 15, Part I, 1-67, 1969.

Huchon, P. and J. Angelier, From subduction to collision; the Suruga-Fujigawa belt, Izu collision zone, central Japan, Bull. Soc. Geol. Fr., (8), III(3), 511-521, 1987.

Huchon, P. and H. Kitazato, Collision of the Izu block with central Japan during the Quaternary and geological evolution of the Ashigara area, Tectonophysics, 110, 201-210, 1984.

Ichikawa, M., Reanalyses of mechanism of earthquakes which occurred in and near Japan, and statistical studies on the nodal plane solutions obtained, 1926-1968, Geophys. Mag., 35, 207-274, 1971.

Ishibashi, K., Re-examination of a great earthquake expected in the Tokai district, central Japan: possibility of the 'Suruga Bay earthquake,' Rep. Coord. Comm. Earthq. Predict., 17, 126-132, 1977 (in Japanese).

Ishibashi, K., Specification of a soon-to-occur seismic faulting in the Tokai district, central Japan, based upon seismotectonics, in Earthquake Prediction: An International Review, Maurice Ewing Series 4, ed. D. W. Simpson and P. G. Richards, pp. 297-332, American Geophysical Union, Washington, D.C., 1981.

Ishida, M., Geometry and relative motion of the Philippine Sea plate beneath the Kanto-Tokai district, Japan, J. Geophys. Res., 97, 489-513, 1992.

Ishida, M., The spatial distribution of earthquake hypocenters and the three-dimensional structure in the Kanto-Tokai district, Japan, J. Phys. Earth, 32, 399-422, 1984.

Kaizuka, S., T. Kiso, T. Machida, Y. Ota, and T. Yoshikawa, Geomorphic development of the drainage basins of the Kiso and Yahiga, central Japan, Geogr. Rev. Jpn., 37, 89-102, 1964.

Vol. 42, No. 1, 1994 
Kanaori, Y., S.-I. Kawakami, and K. Yairi, The block structure and Quaternary rotation of central Japan, Tectonics, 11, 47-56, 1992.

Kanaori, Y., Y. Endo, K. Yairi, and S.-I. Kawakami, A nested fault system with block rotation caused by left-lateral faulting: the Neodani and Atera faults, central Japan, Tectonophysics, 177, 401-418, 1990.

King, G. C. P., R. S. Stein, and J. B. Rundle, The growth of geological structures by repeated earthquakes 1. Conceptual framework, J. Geophys. Res., 93, 13307-13318, 1988.

Lallemant, S., N. Chamot-Rooke, X. LePichon, and C. Rangin, Zenisu Ridge: a deep intraoceanic thrust related to subduction, off southwest Japan, Tectonophysics, 160, 151-174, 1989.

Matsuda, T., Surface faults associated with Kita-Izu earthquake of 1930 in Izu Peninsula, Japan, in The Izu Peninsula, ed. M. Hoshino and H. Aoki, pp. 73-93, Tokai University Press, Tokyo, 1972.

Matsu'ura, M. and T. Sato, A dislocation model for the earthquake cycle at convergent plate boundaries, Geophys. J. Int., 96, 23-32, 1989.

Matsuzaka, S., M. Tohita, and Y. Nakahori, Detection of Philippine Sea plate motion by very long baseline interferometry, Geophys. Res. Lett., 18, 1417-1419, 1991.

McNutt, M. K., M. Diament, and M. G. Kogan, Variations of elastic plate thickness at continental thrust belts, J. Geophys. Res., 93, 8825-8838, 1988.

Mikumo, T. and M. Ando, A search into the faulting mechanism of the 1891 great Nobi earthquake, J. Phys. Earth, 24, 63-87, 1976.

Miyashita, K., A model of plate convergence in southwest Japan, inferred from leveling data associated with the 1946 Nankaido earthquake, J. Phys. Earth, 35, 449-467, 1987.

Mogi, K., Recent horizontal deformation of the earth's crust and tectonic activity in Japan (1), Bull. Earthq. Res. Inst., 48, 413-430, 1970.

Mogi, K., Seismicity in western Japan and long-term earthquake forecasting, in Earthquake Prediction: An International Review, Maurice Ewing Series 4, ed. D. W. Simpson and P. G. Richards, pp. 43-51, American Geophysical Union, Washington, D.C., 1981.

Muramatu, I., Magnitude of the Nobi earthquake, Oct. 28, 1891, Zisin, 15, 341-342, 1962.

Muramatu, I., Distribution of seismic intensity and crustal deformation in the region destroyed by the great Nobi earthquake of October 28, 1891, Res. Rep., Gifu Univ., 3, 202-224, 1963.

Muramatu, I., Neodani fault and Nobi earthquake, Mem. Geol. Soc. Jpn., 12, 117-127, 1976.

Muto, K. and Y. Kawabata, Vertical displacements of bench marks in the Nobi and other districts, Bull Earthq. Res. Inst., Univ. Tokyo, 11, 315-323, 1933.

Okada, Y., Surface deformation due to shear and tensile faults in a half-space, Bull. Seismol. Soc. Am., 75, 1135-1154, 1985.

Otuka, Y., The geomorphology and geology of northern Idu Peninsula, the earthquake fissures of Nov. 26, 1930, and the pre- and post-seismic crust deformations, Bull. Earthq. Res. Inst., Univ. Tokyo, 11, 530-575, 1933.

Pollitz, F. F., Postseismic relaxation theory on the spherical earth, Bull. Seismol. Soc. Am., 82, 422-453, 1992.

Pollitz, F. F. and I. S. Sacks, Modeling of postseismic relaxation following the Great 1857 Earthquake, Southern California, Bull. Seismol. Soc. Am., 82, 454-480, 1992.

Research Group for Explosion Seismology, Regionality of upper mantle around northeast Japan as derived from explosion seismic observations and its seismological implications, Tectonophysics, 37, 117-130, 1977.

Rundle, J. B., An approach to modeling Present-day deformation in southern California, $J$. Geophys. Res., 91, 1947-1959, 1986. 
Rydelek, P. A. and I. S. Sacks, Asthenospheric viscosity inferred from correlated land-sea earthquakes in north-east Japan, Nature, 336, 234-237, 1988.

Rydelek, P. A. and I. S. Sacks, Asthenospheric viscosity and stress diffusion: a mechanism to explain correlated earthquakes and surface deformations in northeast Japan, Geophys. $J$. Inter., 100, 39-58, 1990.

Sato, $\mathrm{H}$. and $\mathrm{N}$. Inouchi, Vertical land movements in Tokai district associated with the Tonankai earthquake of 1944, J. Seismol. Soc. Jpn., Ser. 2, 28, 489-491, 1975.

Sato, T. and M. Matsu'ura, Cyclic crustal movement, steady uplift of marine terraces, and evolution of the island arc-trench system in southwest Japan, Geophys. J. Int., 111, 617-629, 1992.

Sato, T. and M. Matsu'ura, A kinematic model for evolution of island arc-trench systems, Geophys. J. Int., 114, 512-530, 1993.

Scholtz, C. H. and T. Kato, The behavior of a convergent plate boundary: crustal deformation in the South Kanto district, Japan, J. Geophys. Res., 83, 783-797, 1978.

Seno, T., S. Stein, and A. Gripp, A model for the motion of the Philippine Sea plate consistent with NUVEL-1 and geological data, J. Geophys. Res., 98, 17941-17948, 1993.

Stein, R. S., Seismologists' blind faith in surface faults is being dispelled, Earth Space, 2, 8-9, 1990.

Tabei, T., Crustal movements in the inner zone of southwest Japan associated with stress relaxation after major earthquakes, J. Phys. Earth, 37, 101-131, 1989.

Thatcher, W., The earthquake deformation cycle at the Nankai Trough, southwest Japan, $J$. Geophys. Res., 89, 3087-3101, 1984.

Thatcher, W., T. Matsuda, T. Kato, and J. B. Rundle, Lithospheric loading by the 1896 Riku-u earthquake, northern Japan: implications for plate flexure and asthenospheric rheology, $J$. Geophys. Res., 85, 6429-6435, 1980.

Tsuya, H., The Fukozu Fault. A remarkable earthquake fault formed during the Mikawa earthquake of January 13, 1945, Bull. Earthq. Res. Inst., Univ. Tokyo, 24, 59-76, 1946.

Usami, T., Study of historical earthquakes in Japan, Bull. Earthq. Res. Inst., Univ. Tokyo, 54, 399-439, 1979.

Utsu, T., Distribution of hypocenters of earthquakes in and around the Japanese Islands, Kagaku (Science), 44, 739-746, 1974.

Watts, A. B. and M. Talwani, Gravity anomalies seaward of deep-sea trenches and their tectonic implications, Geophys. J. R. Astron. Soc., 36, 57-90, 1974.

Wentworth, C. M., M. C. Blake, Jr., D. L. Jones, A. W. Walter, and M. D. Zoback, Tectonic wedging associated with emplacement of the Fransiscan assemblage, California coast Ranges, in Fransiscan Geology of Northern California, Vol. 43, ed. M. C. Blake, Jr., pp. 163-173, Society of Economic Paleontologists and Mineralogists, Pacific Section, Los Angeles, California, 1984.

Yoshioka, S., The interplate coupling and stress accumulation process of large earthquakes along the Nankai Trough, southwest Japan, derived from geodetic and seismic data, Phys. Earth Planet. Inter., 66, 214-243, 1991.

Yoshioka, S., M. Hashimoto, and K. Hirahara, Displacement fields due to the 1946 Nankaido earthquake in a laterally inhomogeneous structure with the subducting Philippine Sea plate-a three-dimensional finite element approach, Tectonophysics, 159, 121-136, 1989.

Yoshioka, S., T. Yabuki, T. Sagiya, T. Tada, and M. Matsu'ura, Interplate coupling and relative plate motion in the Tokai district, central Japan, deduced from geodetic data inversion using ABIC, Geophys. J. Int., 113, 607-621, 1993.

Vol. 42, No. 1, 1994 